THE PROBLEMS FACING CHILDREN AND THE ROLE OF THE RURAL FAMILY IN CONTROLLING THEM DURING THE SOCIALIZATION PROCESS "A FIELD STUDY AT TWO VILLAGES IN DAKAHLIA GOVERNORATE"

EI-Emam, M.E. and Huda M. E. Salem

Agric. Extension and Rural Sociology Dept., Fac. Agric., Mans.Univ.

المشكلات التى تواجه الأطفال ودور الأسرة الريفية في الرقابـة عليهـا أثثاء عملية

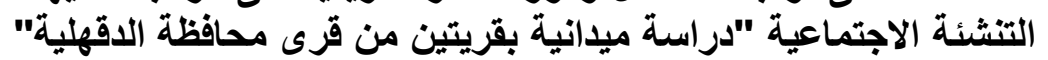

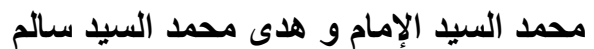

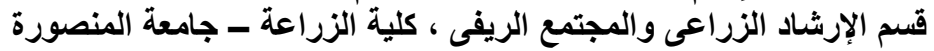

$$
\text { الملخص }
$$

تسعى هذه الدراسة إلى تحقيق هدف رئيسى وهو التعرف على المشكيلات التى تو اجه الأطفال ودور

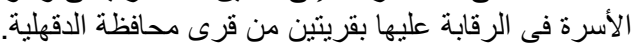

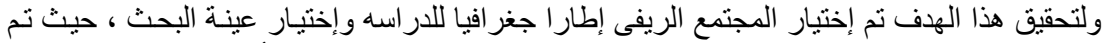

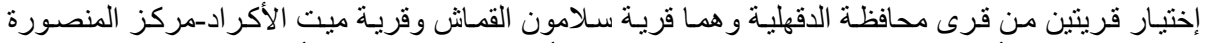

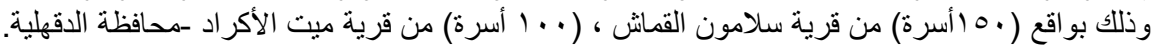

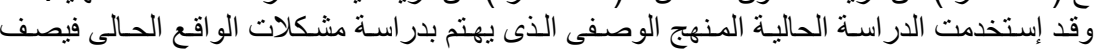

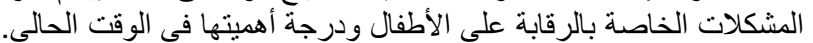

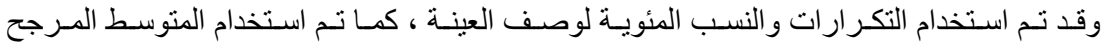
و المتوسط المرجح العام لهذه المشكلات.

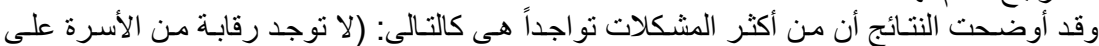

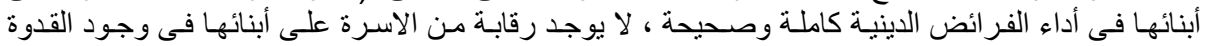

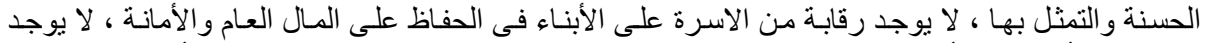

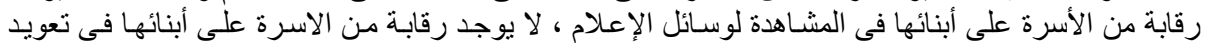

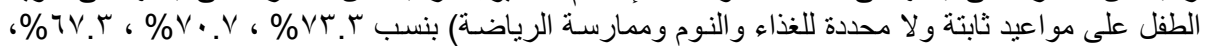

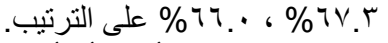

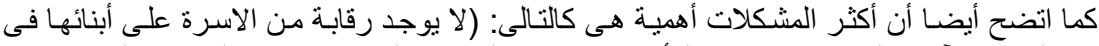

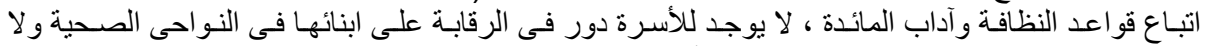

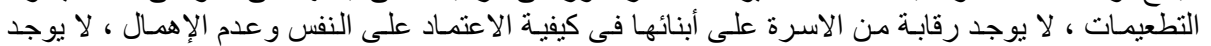

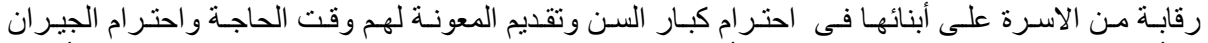

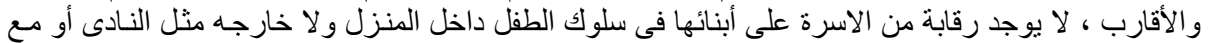

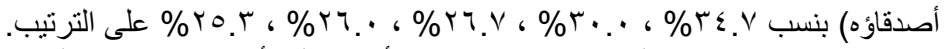

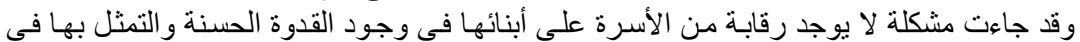

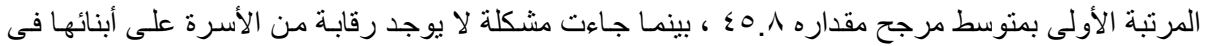

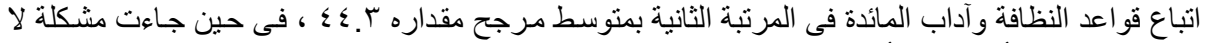

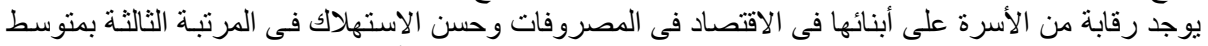

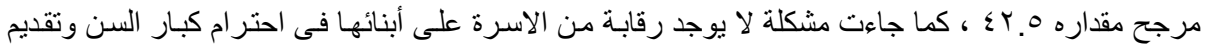

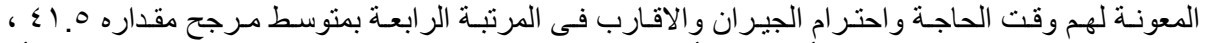

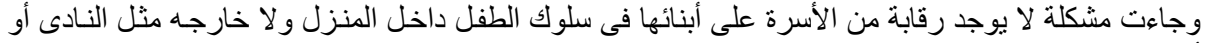

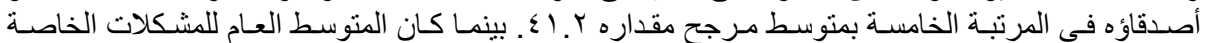

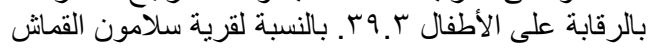




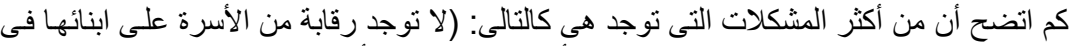

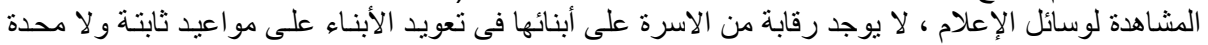

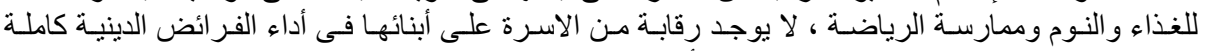

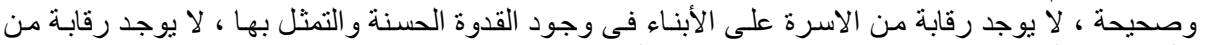

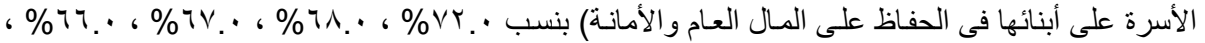

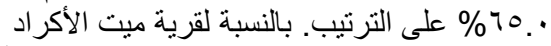

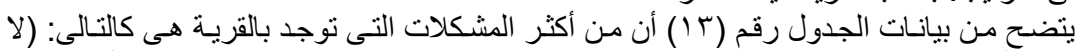

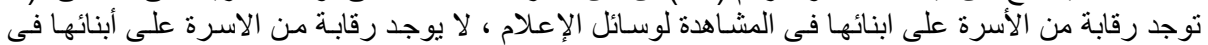

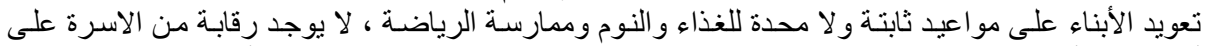

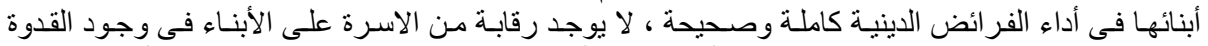

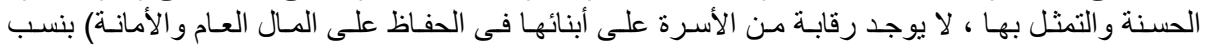

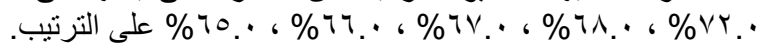

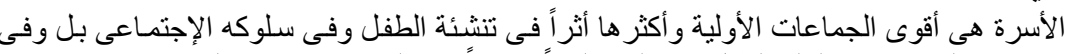
المشكلة البحثية

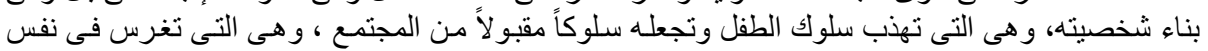

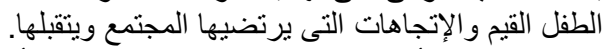

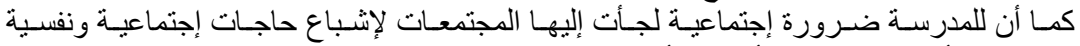

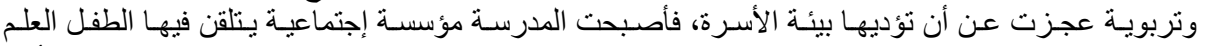

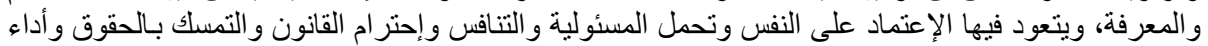

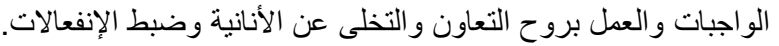

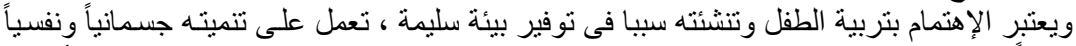

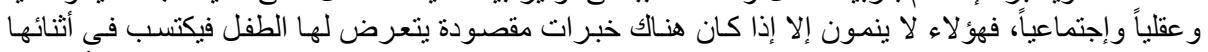

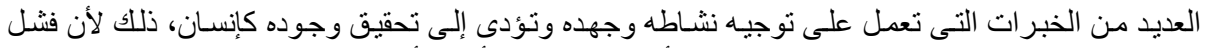

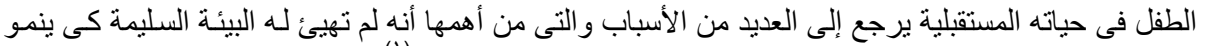

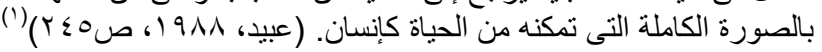

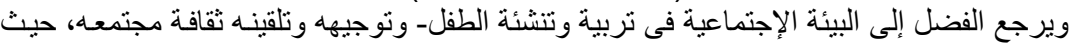

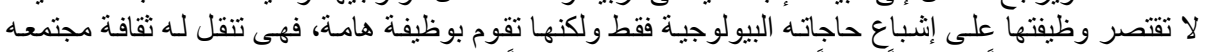

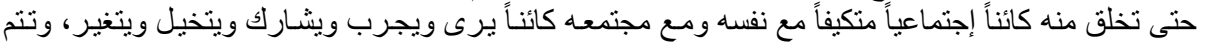

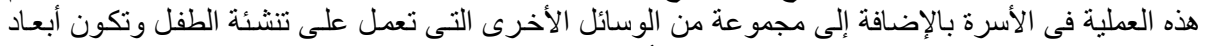

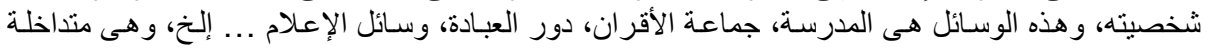

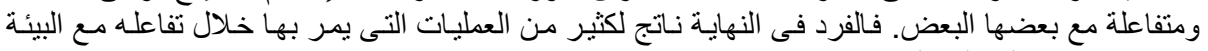
الإجتماعية بوسائلها المختلفة.

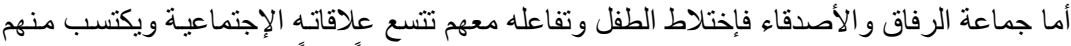

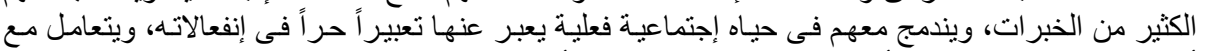

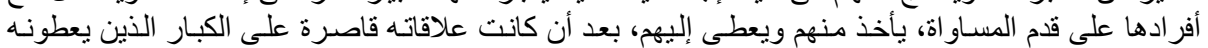

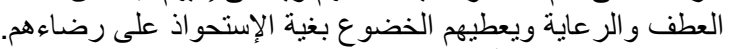

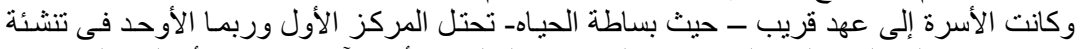

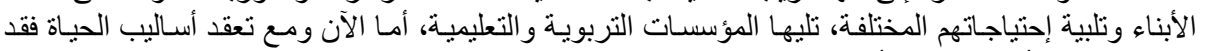

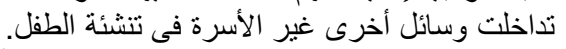

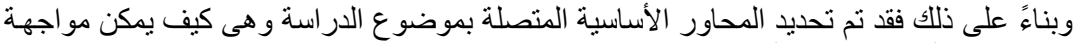

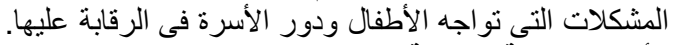
الأهدف البحثية للارت استة تسعى هذه الدر اسة إلى تحقيق هدف رلئيسئى و هو التعرف على المشكلات التى تواجهـ الأطفال ودور الأسرة فى الرقابة عليها بقرى الار اسة.

الإطار النظرى والاستعراض المرجعى 


\section{EL-Emam, M.E. and Huda M. E. Salem}

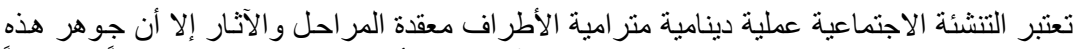

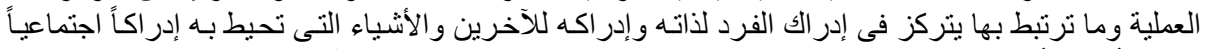

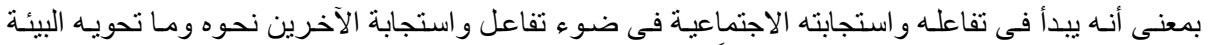

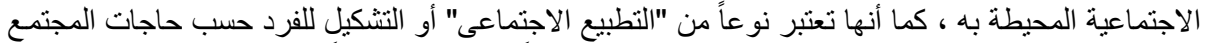

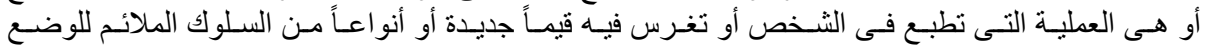

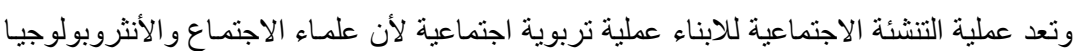
الاجتماعى او العى

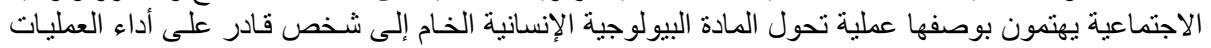
التى يتطلبها منه مجتمعه.

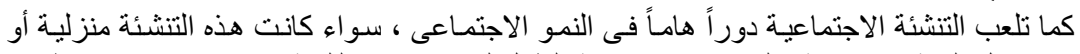

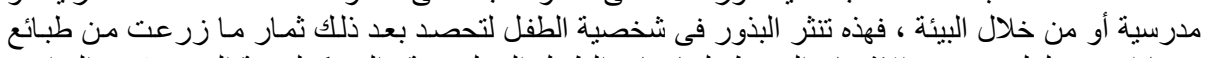

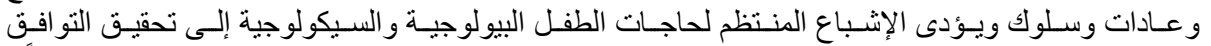

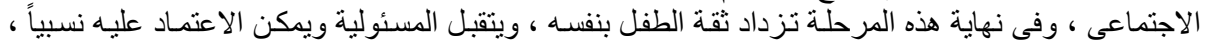

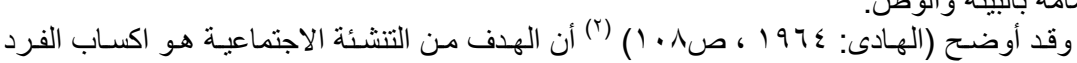
ويزداد اهتمامه بالبيئة و الوطن.

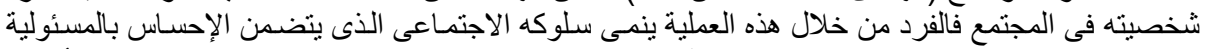

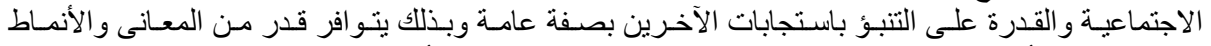

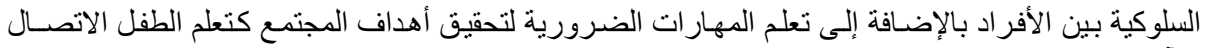

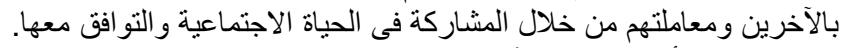

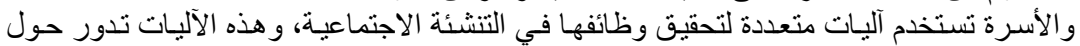

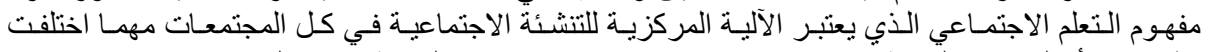

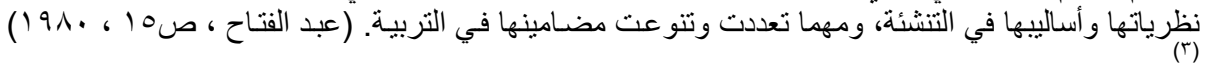

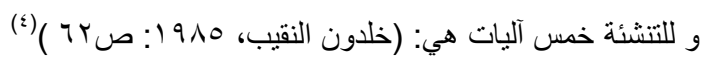

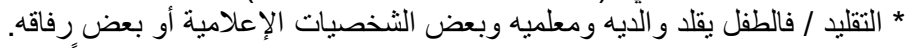

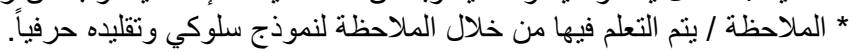

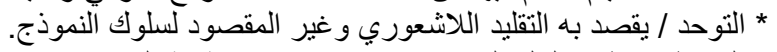

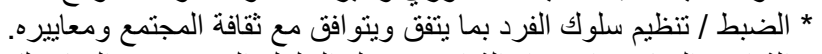

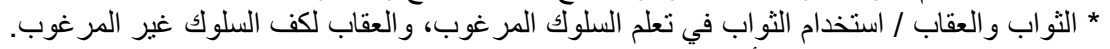

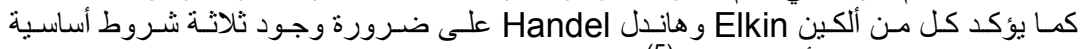

اللتوصل إلى تنشئة اجتماعية ملائمة أو صحيحة.

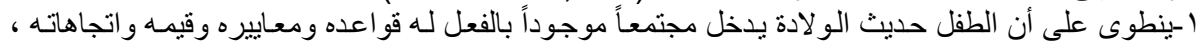

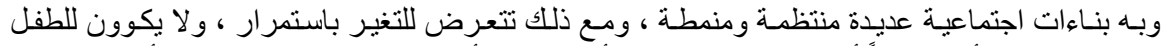

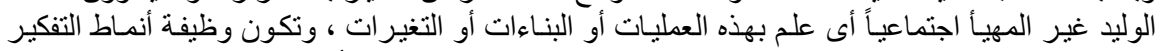

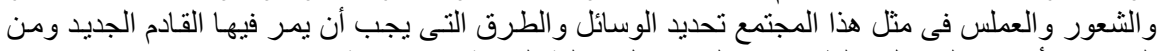

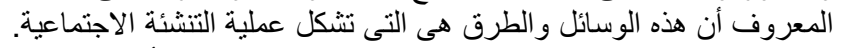

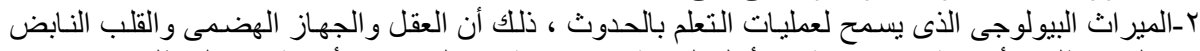

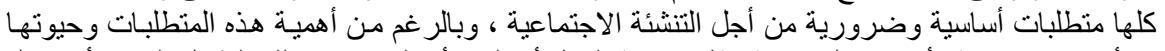

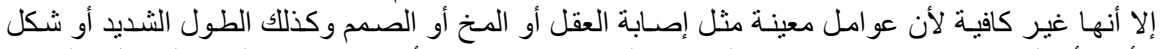

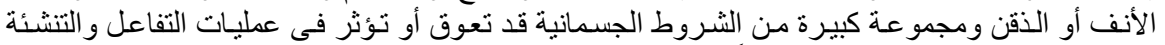

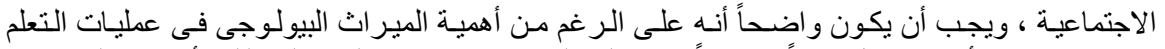

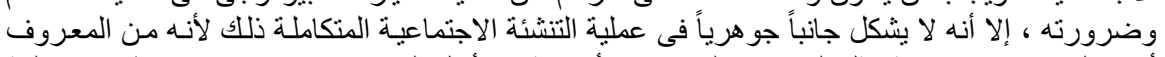

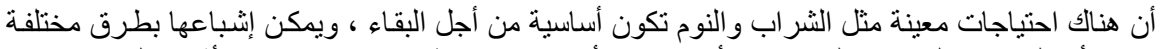

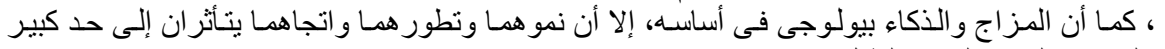

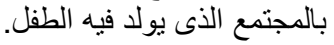

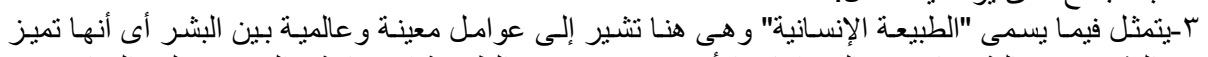

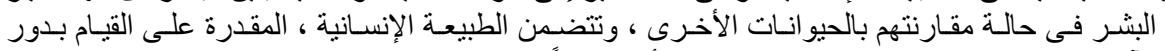

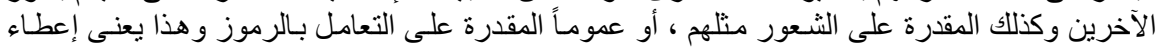




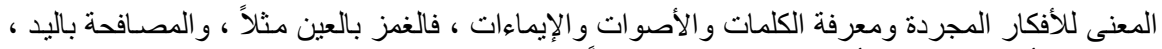

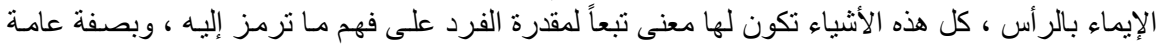

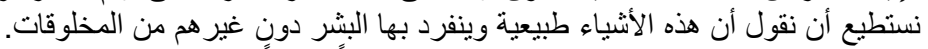

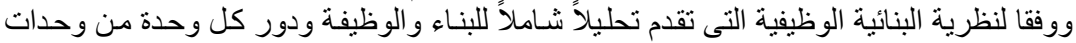

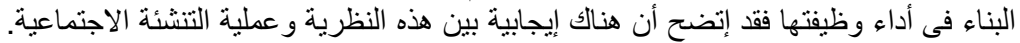
التعريف الإجرائى للتنشئة الاجتماعية

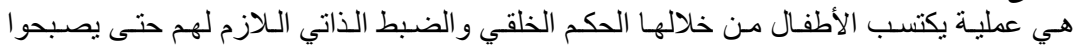
أعضاء ر اشدين مسئولين في مجتمعهم.

\section{الطريقة البحثية}

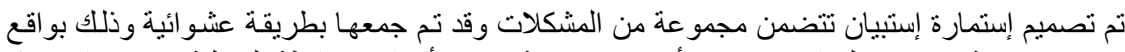

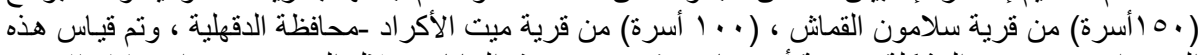

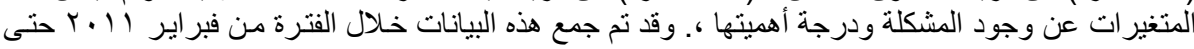

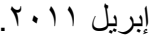

\section{نتائسج الدراسة}

المشكلات التى تواجه الأطفال من وجهة نظر أرباب الأسر:

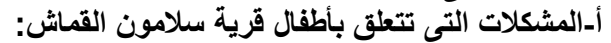

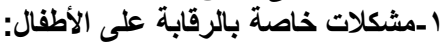

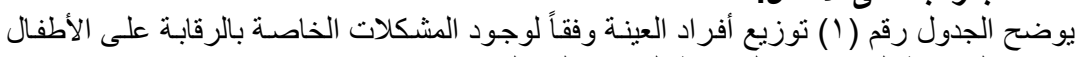

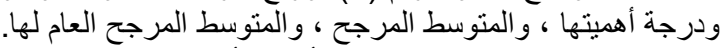

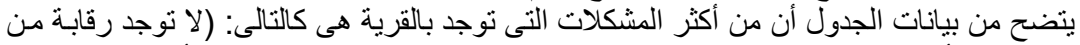

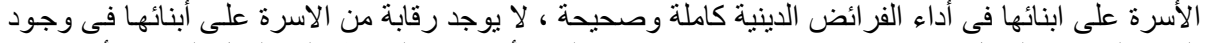

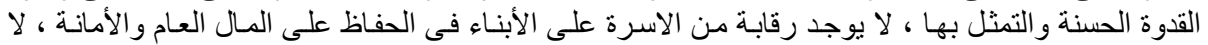

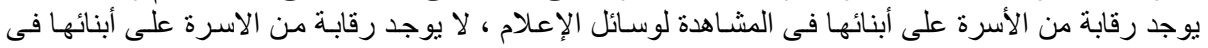

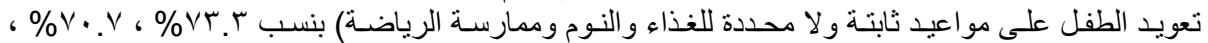

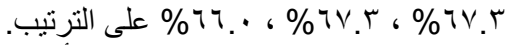

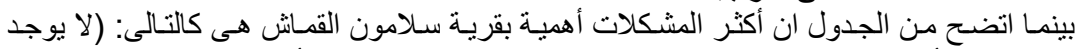

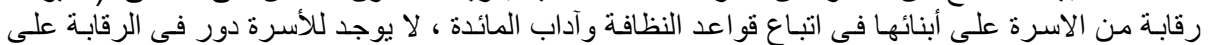

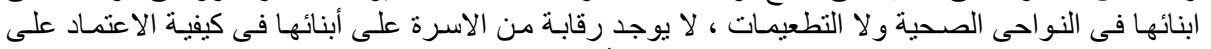

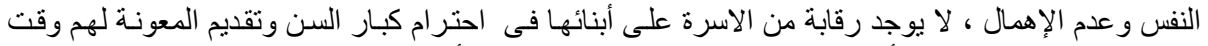

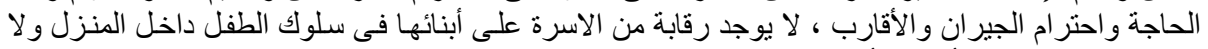

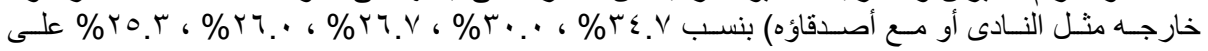
الترتيب.

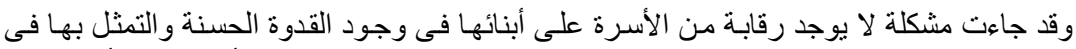

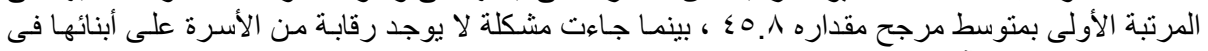

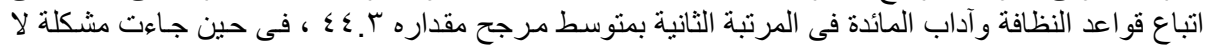

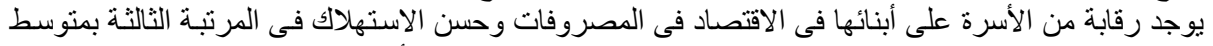

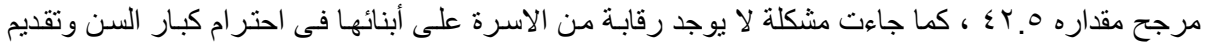

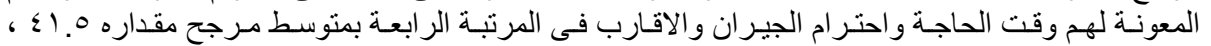

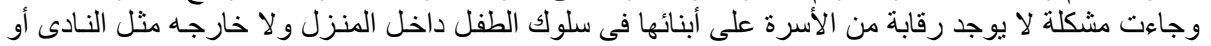

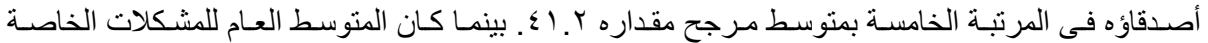

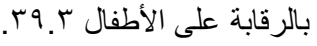


EL-Emam, M.E. and Huda M. E. Salem 
r-مشكلات خاصة بالحاجات الجسمية:

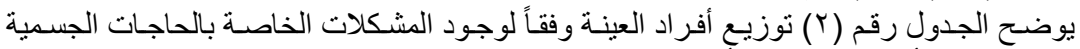

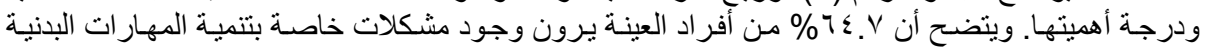

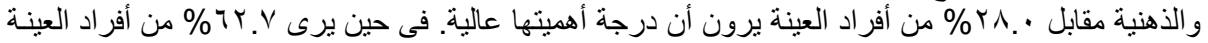

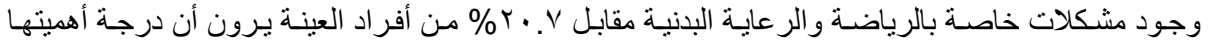

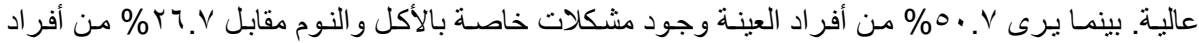
العينة يرون أن درجة أهميتها عالية.

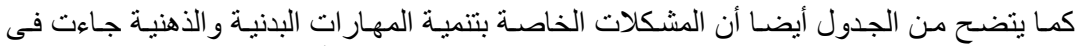

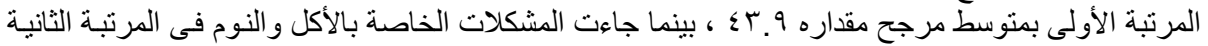

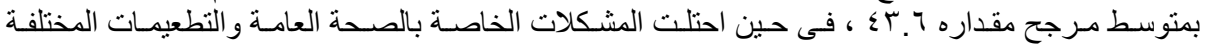

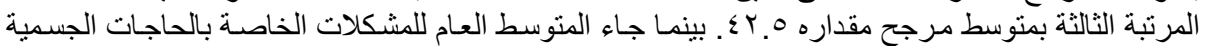

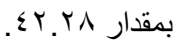

جدول رقم (ץ) :التوزيـع والنسبة المئويـة لعينة المبحوثين بقريـة سـلامون القمـاش وفقاً لوجود المشكلات

\begin{tabular}{|c|c|c|c|c|c|c|c|c|c|c|c|c|c|c|}
\hline \multirow{3}{*}{ المرجح العام } & \multirow{3}{*}{ المرجح } & \multicolumn{8}{|c|}{ درجة الأهمية } & \multicolumn{4}{|c|}{ وجود المشكلة } & \multirow{3}{*}{ المشكــــلات } \\
\hline & & \multicolumn{2}{|c|}{ غير هامة } & \multicolumn{2}{|c|}{ منخفضة } & \multicolumn{2}{|c|}{ متوسطة } & \multicolumn{2}{|c|}{ عالية } & \multicolumn{2}{|c|}{ لا توجد } & \multicolumn{2}{|c|}{ توجد } & \\
\hline & & $\%$ & عدد & $\%$ & 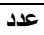 & $\%$ & عدد & $\%$ & عدد & $\%$ & عدد & $\%$ & عدد & \\
\hline \multirow{4}{*}{$\leq r . \wedge$} & $\varepsilon r .7$ & - & - & r.. & $0 \leqslant$ & rv.r & 07 & Y..V & $\varepsilon$. & $\varepsilon 9 . r$ & $V \varepsilon$ & $0 . \mathrm{V}$ & $\sqrt{V 7}$ & | -مشكلات خاصة بالأكل و النوم. \\
\hline & r... & $1 T . r$ & $r$. & | & 0 . & Tr.v & $\leqslant 9$ & $r \cdot v \mid$ & 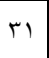 & re & 07 & Tr.V| & $9 \varepsilon$ & 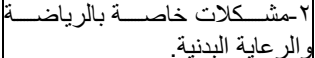 \\
\hline & $\varepsilon r .9$ & - & - & r.. & rq & $00 . r$ & $\Delta r$ & $|1 \wedge . v|$ & rᄉ & ro.r & or & $r \leqslant . V$ & $9 \mathrm{~V}$ & |البدنية والذهنية. خاصة بتنمية المهار ات \\
\hline & $\leq r .0$ & 7. $\mathrm{V}$ & $1 \cdot$ & $\mid \Lambda . V$ & rA & 09.4 & 19 & 10.5 & YT & $07 . \mathrm{V}$ & 10 & $\leq r . r$ & 70 & و ـ-مشعكلات التطعيمات المختلفة بالصحة العامـة \\
\hline
\end{tabular}

r-مشكلات خاصة بالحاجات الاجتماعية: يوضح الجدول رقم (r) توزيع أفر اد العينة وفقاً لوجود المشكلات الخاصـة بالحاجـات الاجتماعيـة ودرجة أهميتها.

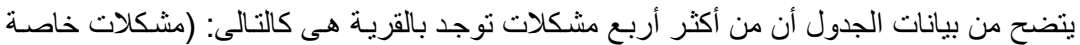

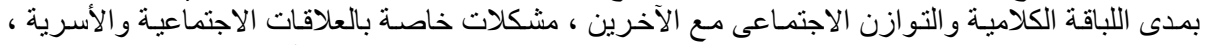

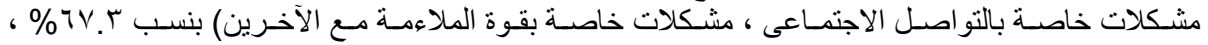

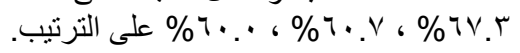

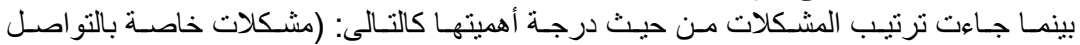

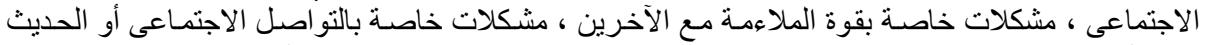

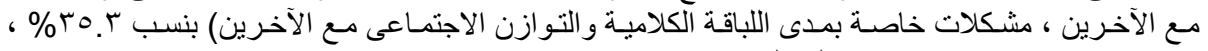

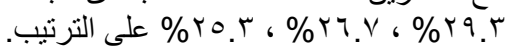

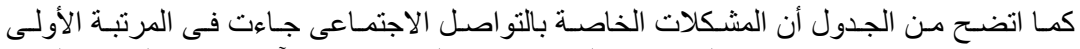

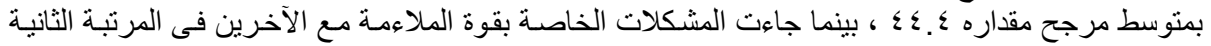

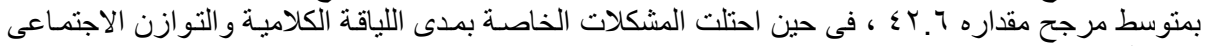

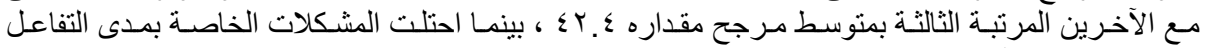

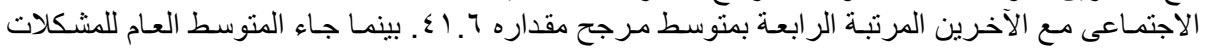

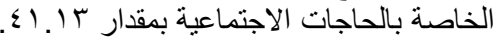

جدول رقم (r) :التوزيـي والنسبة المئويـة لعينة المبحوثين بقريـة سـلامون القمـاش وفقاً لوجود المشكلات الخاصةٌ بالحاجات الاجتماعية ودرجة الهنة أهميتها 


\section{EL-Emam, M.E. and Huda M. E. Salem}

\begin{tabular}{|c|c|c|c|c|c|c|c|c|c|c|c|c|c|c|}
\hline \multirow{3}{*}{ المتوسط المام } & \multirow{3}{*}{ المترجط } & \multicolumn{8}{|c|}{ درجة الأهمية } & \multicolumn{4}{|c|}{ وجود المشكلة } & \multirow{3}{*}{ |لمشكـــلات } \\
\hline & & \multicolumn{2}{|c|}{ غير هامةً } & \multicolumn{2}{|c|}{ منخفضة } & \multicolumn{2}{|c|}{ متوسطة } & \multicolumn{2}{|c|}{ عالية } & \multicolumn{2}{|c|}{ لا توجد } & \multicolumn{2}{|c|}{ توجد } & \\
\hline & & $\%$ & عدد & $\%$ & عدد & $\%$ & عدد & $\%$ & عدد & $\%$ & عدد & $\%$ & عدد & \\
\hline \multirow{9}{*}{$\leqslant 1.1 T$} & 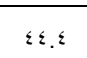 & $7 . \mathrm{V}$ & 1. & ז.. & rq & rr.. & $\leqslant \wedge$ & $|r 0, r|$ & or & rq. & 09 & $7 . \mathrm{V}$ & 9) & 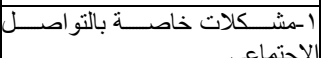 \\
\hline & \multirow{2}{*}{$\leqslant 1}$. & \multirow{2}{*}{$9 . r$} & \multirow{2}{*}{$1 \varepsilon$} & \multirow{2}{*}{ ५^.৩ } & \multirow{2}{*}{$\varepsilon r$} & \multirow{2}{*}{ «1. } & \multirow{2}{*}{$4 \pi$} & \multirow{2}{*}{$r \cdot v \mid$} & \multirow{2}{*}{ r } & \multirow{2}{*}{$\varepsilon \cdot . \gamma$} & \multirow{2}{*}{71} & \multirow{2}{*}{09.4} & \multirow{2}{*}{19} & r -مشـــــاتلات خاصــــة بالجو انــــب \\
\hline & & & & & & & & & & & & & & الاجتماعية. \\
\hline & $r .9$ & 17. $\mathrm{V}$ & ro & r.. & $0 \leqslant$ & r. & $\leqslant \wedge$ & $10 . r$ & rr & rT. & $\varepsilon 9$ & $T Y . r$ & 1.1 & 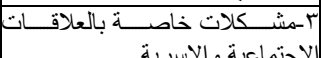 \\
\hline & $\leqslant$ r. $\varepsilon$ & r.r & 。 & ז. & $0 \leqslant$ & ro.r & or & ro.r & rᄉ & r. . V & $\leqslant 9$ & TY.T & $1 \cdot 1$ & 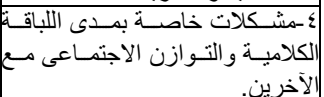 \\
\hline & $\leqslant Y . T$ & 7.. & 1. & rr. & $\leqslant \wedge$ & rr. & $\leqslant \wedge$ & ra.r| & $\leqslant \leqslant$ & $\varepsilon \cdot$. & 7. & $7 \cdot$. & 9. & الآخربن.مشلات خاصة بقوة الملاءمة مـع \\
\hline & $\leqslant 1.7$ & 7.. & 1. & rT.r & 0. & r.. & $0 \leqslant$ & $r \leqslant$. & ד & $\leq 0 . r$ & 71 & $0 \leqslant . Y$ & Ar & 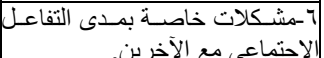 \\
\hline & r१.气 & V.r & 11 & $\leqslant r$. . & ז & $|r, r|$ & $\leqslant v$ & $|19 . r|$ & rq & $0 V_{\text {.r }}$ & $\Lambda_{T}$ & $\varepsilon r . \gamma$ & $T \varepsilon$ & للانفعالات كمعات الآخرين. \\
\hline & $\leq \cdot . \wedge$ & 7.. & 1. & $\leqslant r$. . & זיד & $r \leq . V$ & TV & $|r . . \vee|$ & $\varepsilon$. & $00 . r$ & ה & 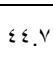 & TV & 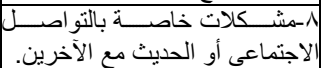 \\
\hline
\end{tabular}

ع -مشكلات الحاجات لتحمل المسئولية بالنسبة للطقل:

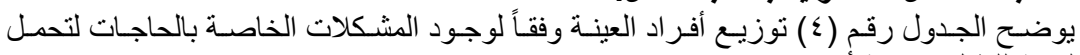

المسئولية بالنسبة للطفل ودرجة أهميتها .

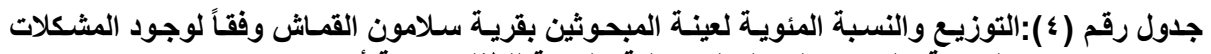
الخاصة بالحاجات لتحمل المسئولية بالنسبة للطفل ودرجة التربة أهميتها

\begin{tabular}{|c|c|c|c|c|c|c|c|c|c|c|c|c|c|c|}
\hline \multirow{3}{*}{ المرجح العام } & \multirow{3}{*}{ المترجط } & \multicolumn{8}{|c|}{ درجة الأهمية } & \multicolumn{4}{|c|}{ وجود المشكلة } & \multirow{3}{*}{ المشكــــلات } \\
\hline & & \multicolumn{2}{|c|}{ غير هامة } & \multicolumn{2}{|c|}{ | منخفضة } & \multicolumn{2}{|c|}{ متوسطة } & \multicolumn{2}{|c|}{ عالية } & \multicolumn{2}{|c|}{ لا توجد } & \multicolumn{2}{|c|}{ توجد } & \\
\hline & & $\%$ & عدد & $\%$ & عدد & $\%$ & عدد & $\%$ & عدد & $\%$ & عدد & $\%$ & عدد & \\
\hline \multirow{4}{*}{$\varepsilon r . r$} & $\leq \cdot .1$ & Ir.r & r. & $|r+r|$ & 0. & r.. & ra & rv.r| & $\leqslant 1$ & «ะ.. & 77 & 07. & $\wedge \varepsilon$ & 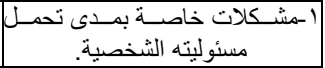 \\
\hline & $\leq ะ .9$ & - & - & ri. & ra & $|\leqslant \Lambda . V|$ & $V T$ & ro.r & $r_{\Lambda}$ & ז. & $0 \leqslant$ & $T \leqslant$. & 97 & 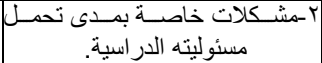 \\
\hline & $\leq \leqslant .0$ & - & - & $0 . r$ & ra & or.y & va & rr. & rT & $0 . \mathrm{V}$ & VT & $\varepsilon 9 . r$ & $v \varepsilon$ & 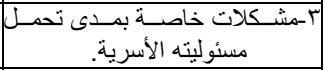 \\
\hline & $\leq r . r$ & 7.9 & 1. & r.v. & $\leqslant 9$ & r.. & rq & $r \leqslant . v \mid$ & or & rq.r & 09 & $7 . \mathrm{V}$ & 91 & 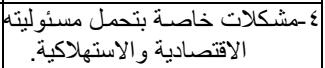 \\
\hline
\end{tabular}

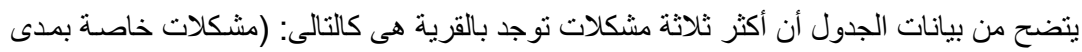

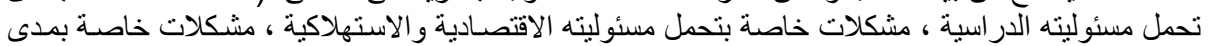

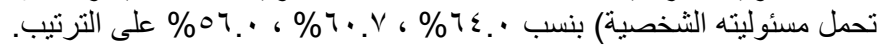

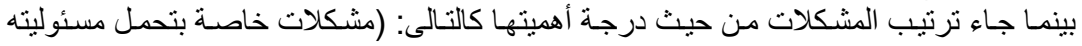

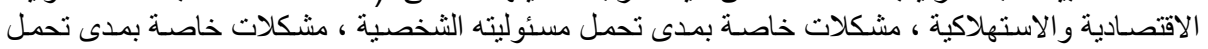

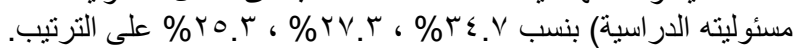

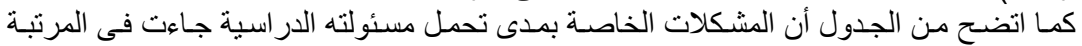

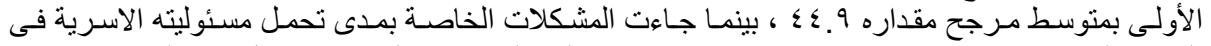

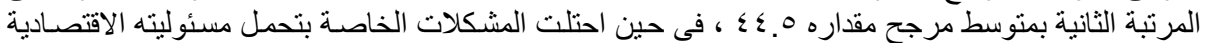

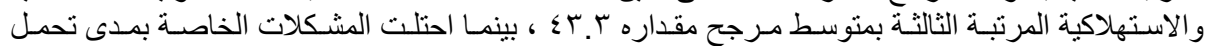

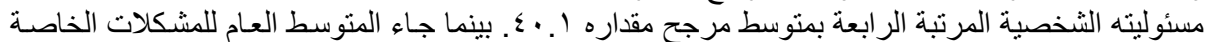

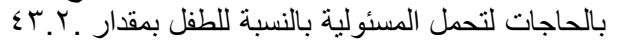


0-مشكلات خاصة بالحاجات النفسية:

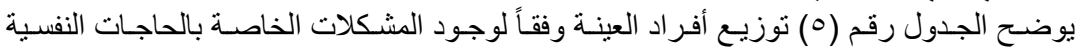

رقم (0):التوزيع والنسبة المئويـة لعينة المبحوثين بقرية سـلامون القماش وفقاً لوجود المشكلات الخاصة

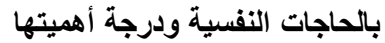

\begin{tabular}{|c|c|c|c|c|c|c|c|c|c|c|c|c|c|c|}
\hline \multirow{3}{*}{ المرجح العام } & \multirow{3}{*}{ المرجح } & \multicolumn{8}{|c|}{ لدرجة الأهمية } & \multicolumn{4}{|c|}{ وجود المشكلة } & \multirow{3}{*}{ المشكـــلات } \\
\hline & & \multicolumn{2}{|c|}{ غير هامة } & \multicolumn{2}{|c|}{ منخفضة } & \multicolumn{2}{|c|}{ متوسطة } & \multicolumn{2}{|c|}{ عالية } & \multicolumn{2}{|c|}{ لا توجد } & \multicolumn{2}{|c|}{ توجد } & \\
\hline & & $\%$ & عدد & $\%$ & عدد & $\%$ & عدد & $\%$ & عدد & $\%$ & عدد & $\%$ & عدد & \\
\hline \multirow{4}{*}{$\varepsilon \cdot . \Sigma \Lambda$} & «.. & 9.4 & $1 \leq$ & rA.V & $\leqslant r$ & $\leqslant 1 . r$ & 74 & $r \cdot . r$ & rI & $\leqslant 7 . V$ & $\checkmark \cdot$ & or.r & $\wedge$. & 1 -مشكلات خاصة بالتو ازن النفسى. \\
\hline & rı. & $1 \cdot$ & 10 & r.. & $0 \leqslant$ & $\leqslant \varepsilon . V$ & TV & 9. & $1 \varepsilon$ & r. & $\leq 9$ & $T V . r$ & 1.1 & 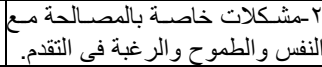 \\
\hline & $\varepsilon \cdot .7$ & r.t & . & $\leqslant r$. & זדי & ro.r & or & $19 . r$ & rq & $r 9 . r$ & 09 & $7 \cdot . \mathrm{V}$ & 91 & 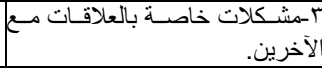 \\
\hline & «. $\mathrm{v}$ & $7 . \mathrm{Y}$ & 1. & rr. & $\varepsilon \wedge$ & rı. & ov & T.r & ro & $\leqslant \cdot$. & 7. & $7 \cdot .$. & 9. & ـ -مشكلات خاصة بالانطو ائية. \\
\hline
\end{tabular}

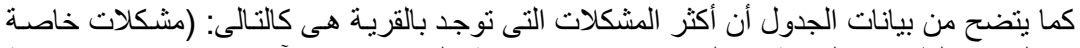

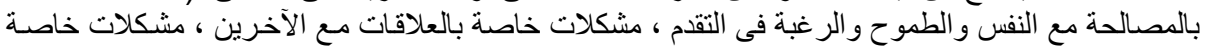

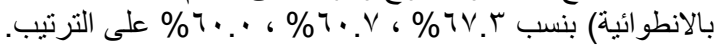

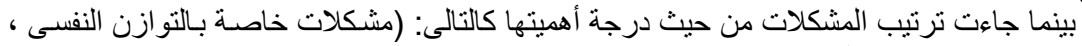

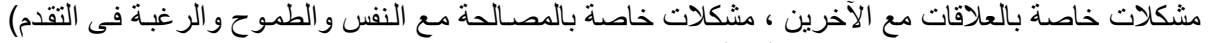

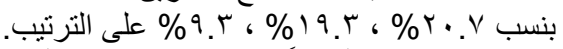

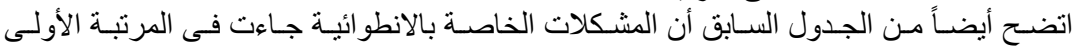

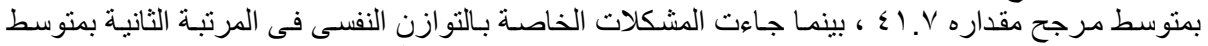

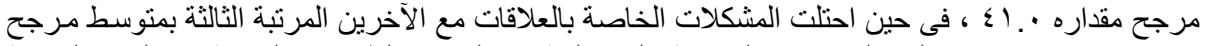

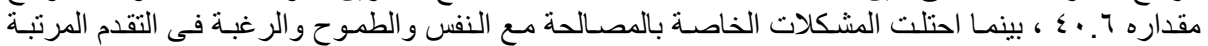

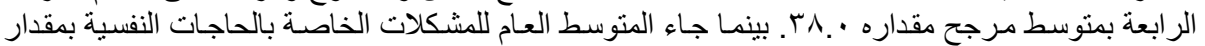

7-مشكلات خاصة بالحاجات الثقافية:

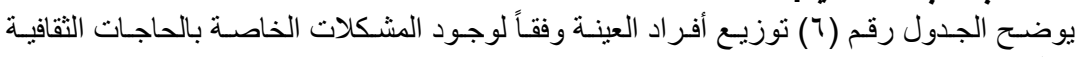
ودرجة أهميتها .

جدول رقم (ך):التوزيـع والنسبة المئويـة لعينـة المبحوثين بقريـة سـلامون القمـاش وفقاً لوجـود المشكلات

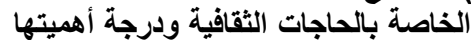

\begin{tabular}{|c|c|c|c|c|c|c|c|c|c|c|c|c|c|c|}
\hline \multirow{3}{*}{ المرجط } & \multirow{3}{*}{ المرجح } & \multicolumn{8}{|c|}{ درجة الأهمية } & \multicolumn{4}{|c|}{ وجود المشكلة } & \multirow{3}{*}{ |المشكــــلات } \\
\hline & & \multicolumn{2}{|c|}{ غيز هامة } & \multicolumn{2}{|c|}{ منخفضة } & \multicolumn{2}{|c|}{ متوسطة } & \multicolumn{2}{|c|}{ عالية } & \multicolumn{2}{|c|}{ لا توجد } & \multicolumn{2}{|c|}{ توجد } & \\
\hline & & $\%$ & 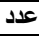 & $\%$ & عدد ع اد & $\%$ & عدد & $\%$ & عدد & $\%$ & عدد & $\%$ & عدد & \\
\hline \multirow{4}{*}{$\varepsilon 1 . r_{0}$} & $\leq \cdot .7$ & $7 . \mathrm{V}$ & 1. & TT.r & 0. & $\leqslant r . V$ & $7 \varepsilon$ & IV.r & Y & Tr.V & $\leqslant 9$ & 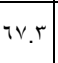 & 1.1 & 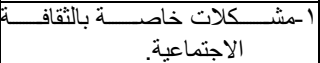 \\
\hline & r9.r & $V . r$ & 11 & r4. & $0 \leqslant$ & $\leqslant \leqslant$. & 77 & $I T . V$ & 19 & $\sum \leqslant . V$ & TV & $00 . r$ & AT & r-مشكلات خاصة بالثقافة الأسرية. \\
\hline & $\leq \varepsilon .0$ & - & - & ז. (ז. & $0 \leqslant$ & $r, r$ & $\leqslant V$ & r... & $\leqslant 9$ & $\leqslant r . V$ & $7 \varepsilon$ & $O V_{.} r$ & $\Lambda_{T}$ & 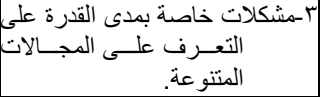 \\
\hline & «1. & 17.5 & r. & ז.rT & 0. & $r \cdot{ }^{\prime} \cdot$ & $r \cdot$ & $r+r$ & 0. & rV.r & 07 & $T . Y$ & $9 \leq$ & ــ الأخرى. \\
\hline
\end{tabular}

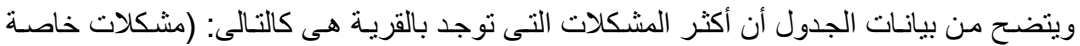

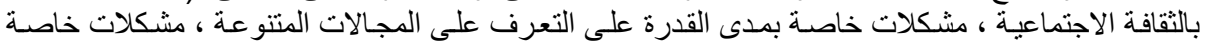

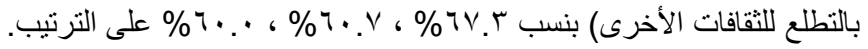




\section{EL-Emam, M.E. and Huda M. E. Salem}

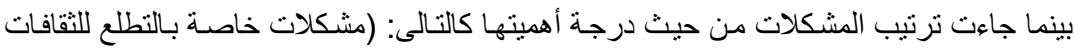

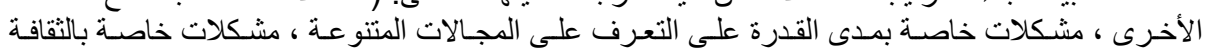

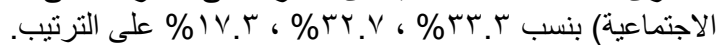

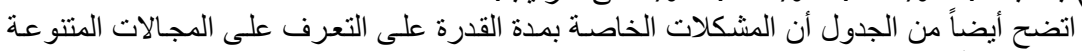

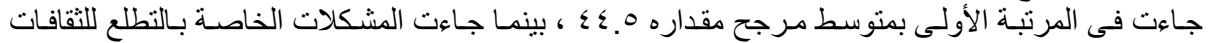

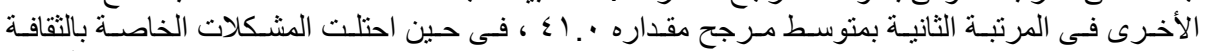

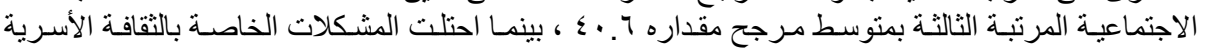

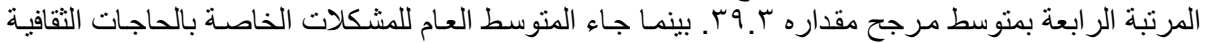

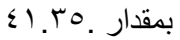
V Vشكلات خاصة بالحاجات الاقتصادية: يوضح الجدول رقم (V) توزيع أفر اد العينـة وفقاً لوجود المشكلات الخاصـة بالحاجـات الاقتصـادية ودرجة أهميتها.

جدول رقم (V):التوزيـع والنسبة المئويـة لعينـة المبحوثين بقريـة سـلامون القمـاش وفقاً لوجود المشكلات

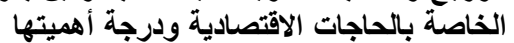

\begin{tabular}{|c|c|c|c|c|c|c|c|c|c|c|c|c|c|c|}
\hline \multirow{3}{*}{ المرتوسط } & \multirow{3}{*}{ المترجط } & \multicolumn{8}{|c|}{ درجة الأهمية } & \multicolumn{4}{|c|}{ وجود المشكلة } & \multirow{3}{*}{ المشكــــلات } \\
\hline & & \multicolumn{2}{|c|}{ غير هامة } & \multicolumn{2}{|c|}{ منخفضة } & \multicolumn{2}{|c|}{ متوسطة } & \multicolumn{2}{|c|}{ عالية } & \multicolumn{2}{|c|}{ لا توجد } & \multicolumn{2}{|c|}{ توجد } & \\
\hline & & $\%$ & عدد & $\%$ & عدد & $\%$ & عدد & $\%$ & عدد & $\%$ & عدد & $\%$ & عدد & \\
\hline \multirow{4}{*}{ ET.KT } & $\leqslant \leqslant .9$ & - & - & r.. & rq & $\leqslant \Lambda . V$ & $v^{r}$ & ro.r & 广A & र१. & $\varepsilon \varepsilon$ & $v \cdot . v$ & 1.7 & 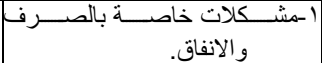 \\
\hline & $\leqslant 0.0$ & - & - & $|\wedge\rangle$. & rᄉ & 09.4 & 19 & rr. & ז & «ะ. & 77 & 07. & $\lambda \varepsilon$ & 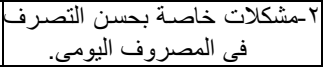 \\
\hline & $\varepsilon r . \leqslant$ & 7.. & 1. & r.. & rq & $r \wedge . v$ & 01 & $\gamma \wedge . \gamma$ & $\varepsilon r$ & $r q . r$ & 09 & $7 . \mathrm{V}$ & १1 & |r-مشكلات خاصة بحسن الاستهلاك \\
\hline & $r 9.1$ & $9 . \%$ & $1 \varepsilon$ & $r \leqslant . V$ & or & $\leqslant r$. & זי & $1 \leq$. & r) & $\varepsilon \cdot V$ & 71 & 09.4 & $\wedge 9$ & 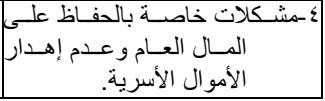 \\
\hline
\end{tabular}

المصدر: المتمارة الاستبيان.

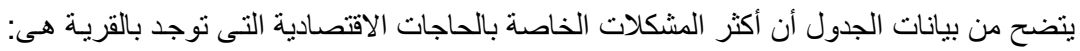

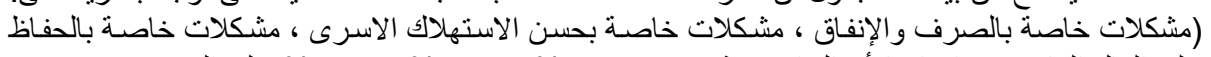

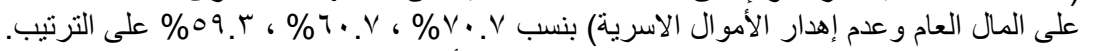

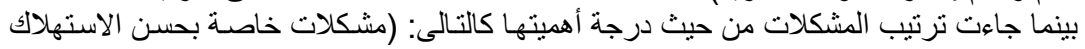

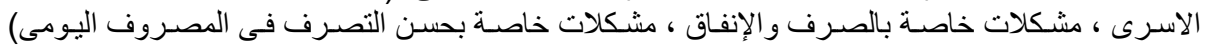

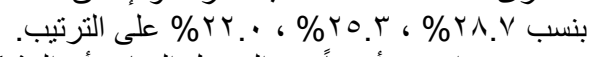

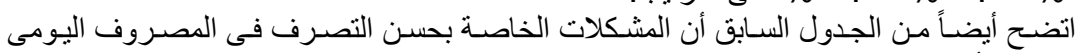

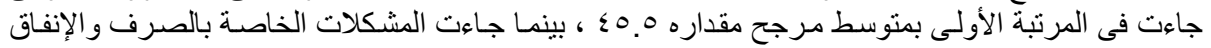

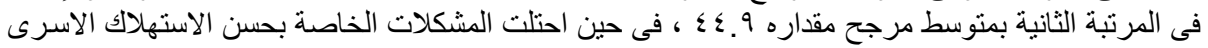

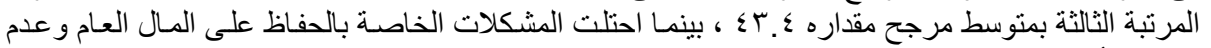

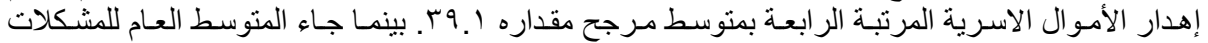

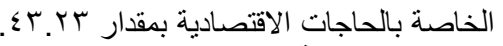
1-مشكلات خاصة بالتوجيه:

يوضح الجدول رقم (^) توزيع أفر اد العينة وفقاً لوجود المشكلات الخاصة بالتوجيه ودرجة أهميتها

جدول رقم (^):التوزيـع والنسبة المئويـة لعينـة المبحوثين بقريـة سـلامون القمـاش وفقاً لوجود المشكلات الخاصة بالتوجيه ودرجة أهميتها

\begin{tabular}{|c|c|c|c|c|c|c|c|c|}
\hline \multirow{3}{*}{ المرجح العتر } & \multirow{3}{*}{ المرجح } & \multicolumn{4}{|c|}{ لدرجة الأهمية } & \multicolumn{2}{|c|}{ وجود المشكلة } & \multirow{3}{*}{ |المشكـــلات } \\
\hline & & غير هامة & منذفضة & متوسطة & عالية & لا توجد & توجد & \\
\hline & & \begin{tabular}{l|l} 
\% عدد \\
\end{tabular} & ع عدد & \begin{tabular}{l|l|}
$\%$ & ع
\end{tabular} & \% ع ع & عدد & عدد ( عد & \\
\hline
\end{tabular}


J. Agric. Econom. and Social Sci., Mansoura Univ., Vol.2 (5), May, 2011

\begin{tabular}{|c|c|c|c|c|c|c|c|c|c|c|c|c|c|c|}
\hline \multirow{5}{*}{ ए৭.v^ } & $r \Lambda .9$ & $1 \cdot \cdot$ & 10 & rד. & $0 \leqslant$ & $r \wedge . v \mid$ & 01 & 10.4 & rT & r..V & $\leqslant$ & $V T . T$ & 11. & | -سوء توجيه المعلم للتلاميذ. \\
\hline & $\leqslant Y . \leqslant$ & $r . r$ & 。 & r4. & $0 \leqslant$ & ro.r| & or & ro.r & $r_{\Lambda}$ & $r ד . V$ & $\varepsilon$. & VT.T & 11. & 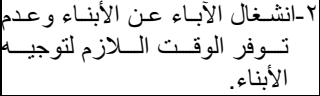 \\
\hline & r9.7 & $1 r . r$ & $r$. & rr. & $\leqslant \wedge$ & rr. & $\leqslant \wedge$ & rr. & $\Gamma \varepsilon$ & $r \leqslant$. & 01 & 7.. & 99 & 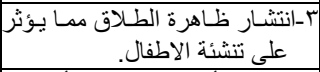 \\
\hline & $\leqslant 1.7$ & 7. . & 1. & rr.tr & 0. & r.. & $0 \leqslant$ & $r \leq$. & rq & r..v & $\leqslant 9$ & $T V . r$ & 1.1 & ـ ـانتشار الأمية بين بعض الأمهات. \\
\hline & rา. & $1 \leq$. & r) & $\leqslant r$. & זיד & $|r 1 . r|$ & $\leqslant V$ & $1 . \mathrm{V}$ & 19 & $01 . r$ & VV & $\{\Lambda, v$ & $V r$ & 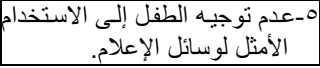 \\
\hline
\end{tabular}

يتضح من بيانات الجدول أن أكثر المشكلات الخاصة بالتوجيه التى توجد بالقرية هي: (سوء توجيه

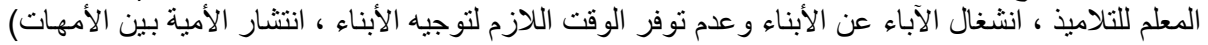

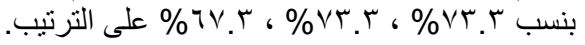

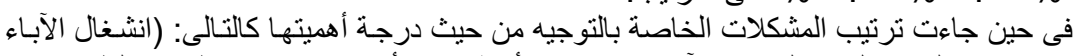

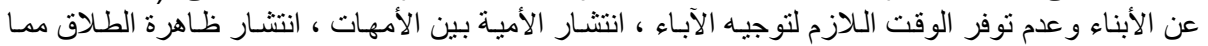

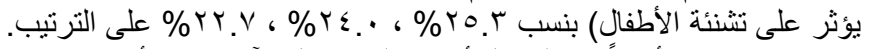

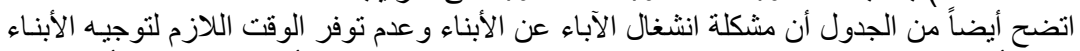

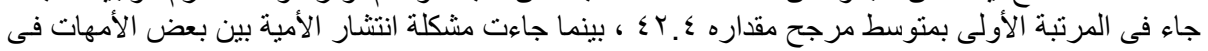

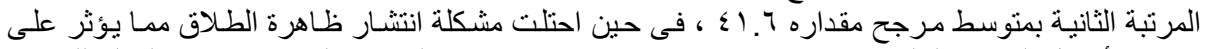

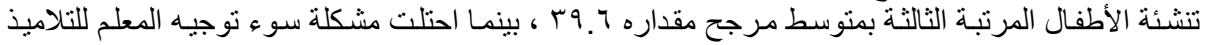

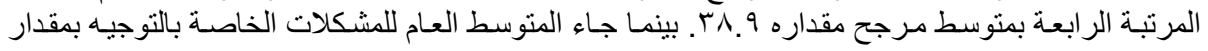

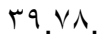

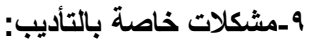
يوضـح الجـول رقم (9) توزيـع أفر اد العينـة وفقاً لوجود المشكلات الخاصـة بالتاديب ودرجـة

جدول رقم (9):التوزيع و النسبة المئويـة لعينة المبحوثين بقريـة سـلامون القمـاش وفقاً لوجود المشكلات

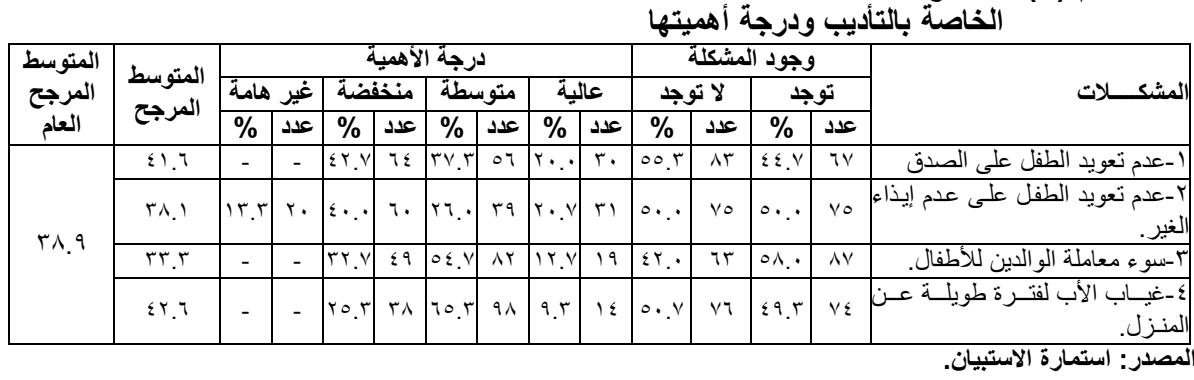

يتضح من بيانات الجدول أن أكثر المشكلات الخاصة بالتأديب التى توجد بالقرية هى: (سوء معاملة

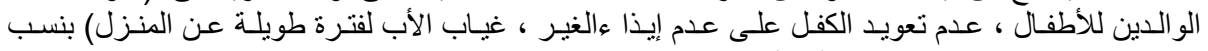
.

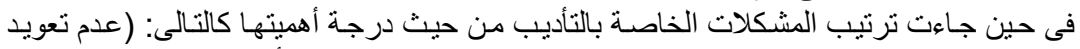

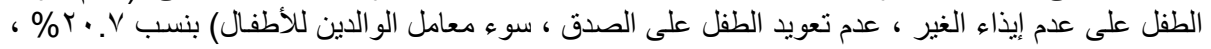

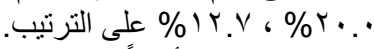

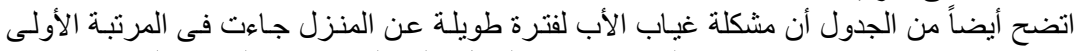

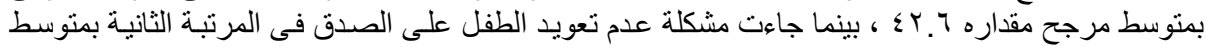

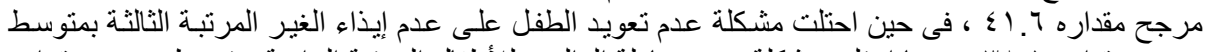

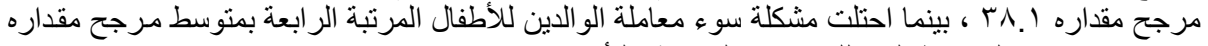

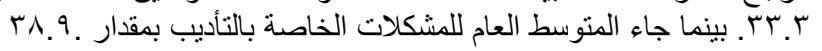




\section{EL-Emam, M.E. and Huda M. E. Salem}

• 1 -مثكلات خاصة بالر عاية أو التحكم:

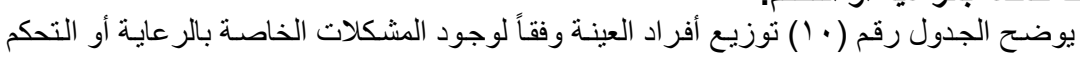
ودرجة أهميتها.

جدول رقم ( • 1):التوزيع والنسبة المئويـة لعينـة المبحوثين بقريـة سـلامون القمـاش وفقاً لوجود المشكلات الخاصة بالرعاية او التحكم ودرجة أهميتها

\begin{tabular}{|c|c|c|c|c|c|c|c|c|c|c|c|c|c|c|}
\hline \multirow{3}{*}{ المرجتح العام } & \multirow{3}{*}{ المتوسط } & \multicolumn{8}{|c|}{ درجة الأهمية } & \multicolumn{4}{|c|}{ وجود المثكلة } & \multirow{3}{*}{ المشكــــلات } \\
\hline & & \multicolumn{2}{|c|}{ غير هامة } & \multicolumn{2}{|c|}{ منخفضة } & \multicolumn{2}{|c|}{ متوسطة } & \multicolumn{2}{|c|}{ عالية } & \multicolumn{2}{|c|}{ لا توجد } & \multicolumn{2}{|c|}{ توجد } & \\
\hline & & $\%$ & عدد & $\%$ & عدد & $\%$ & عدد & $\%$ & عدد & $\%$ & عدد & $\%$ & عدد & \\
\hline \multirow{5}{*}{ rq.r } & $\leq r . \varepsilon$ & 7.9 & 1. & r.. & rq & r^.v| & 01 & $r \wedge . \gamma \mid$ & $\varepsilon r$ & $\leq 0 . r$ & 71 & $0 \leqslant . V$ & NY & 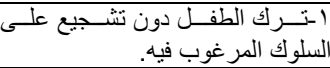 \\
\hline & rq. & 9.4 & $1 \leqslant$ & $|r 0 . r|$ & or & $\leqslant 1 . r$ & Tr & $1 \leq .0$ & r) & or.r & ᄉ. & $\leqslant 4 . V$ & $v \cdot$ & 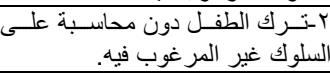 \\
\hline & $r v$. & $1 \cdot$. & 10 & rr. & $0 \leqslant$ & $01 . r$ & VV & r.v & $\varepsilon$ & r.. V & $\leqslant$. & VT.T & 11. & أمام رغبترضه الآراء على الطفل و الوقوف \\
\hline & rی.o & $1 \cdot$ & 10 & r4. & $0 \leqslant$ & $\mid \leqslant 1, r$ & TT & $|r . y|$ & 19 & (ז.r & 0 . & $74 . \mathrm{V}$ & $1 \cdots$ & لأبنائهم. \\
\hline & r৯. v & rer & $r$. & rr. & $\leqslant \wedge$ & $r \Lambda_{.} \cdot$ & or & $17 . \mathrm{V}$ & ro & $r \leqslant$. & 01 & 77. & 99 & التى يجيب أن يقابة عن الطفل بالمسئوليات \\
\hline
\end{tabular}

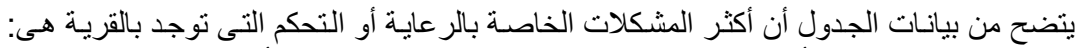

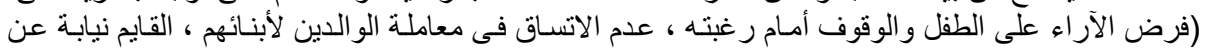

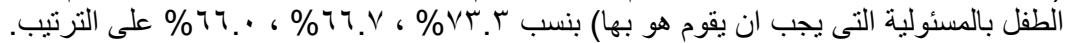

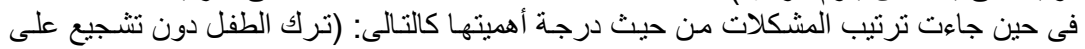

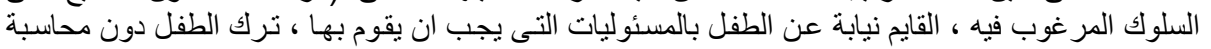

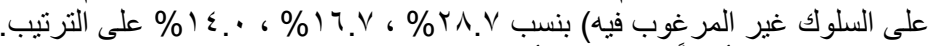

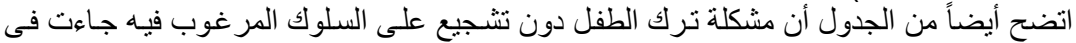

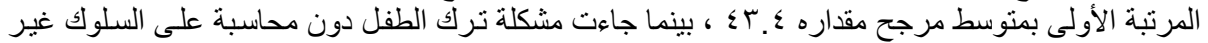

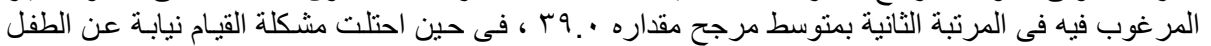

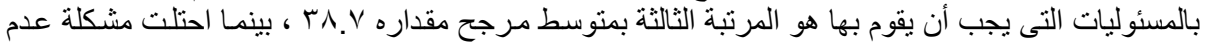

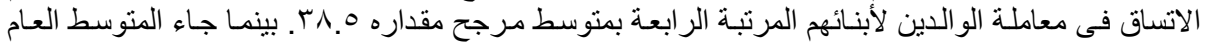

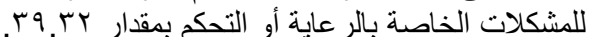

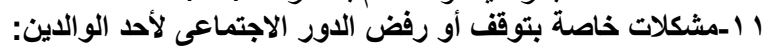

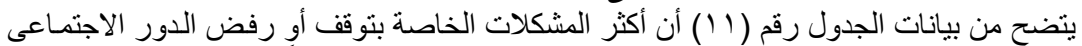

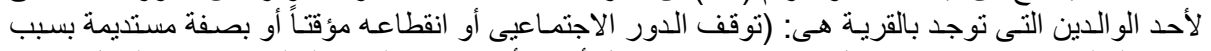

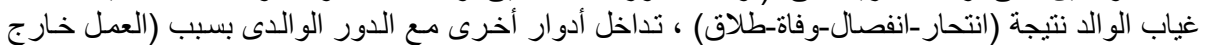

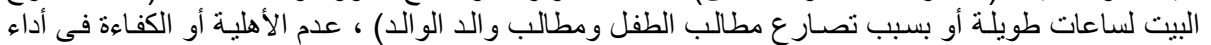

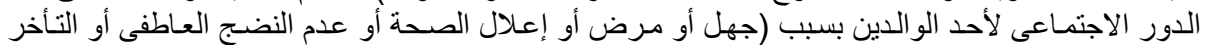

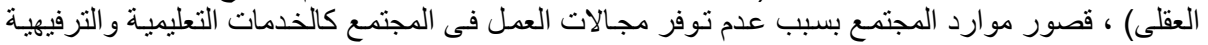

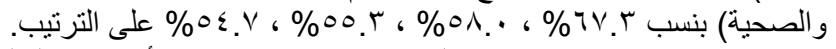

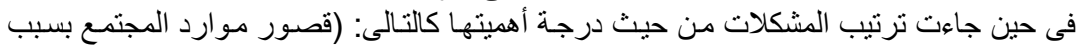

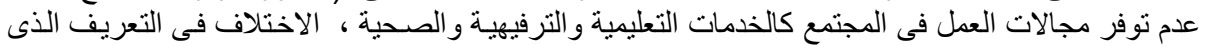

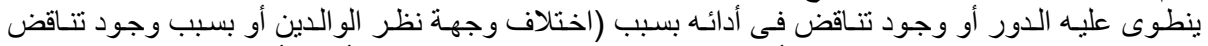

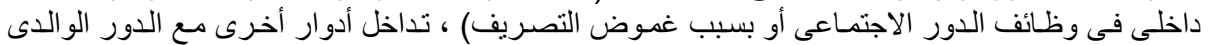

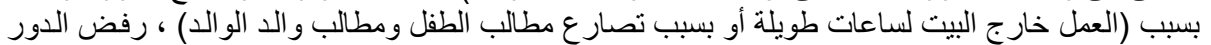

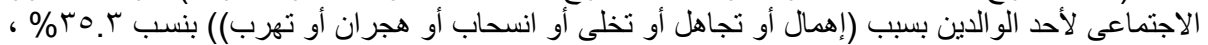

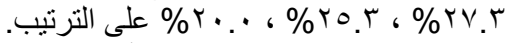

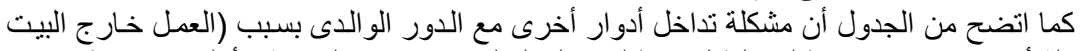

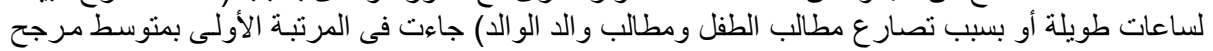




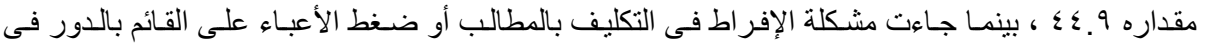

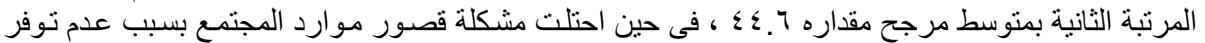

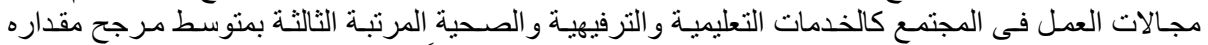

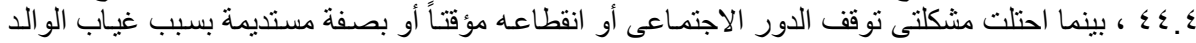

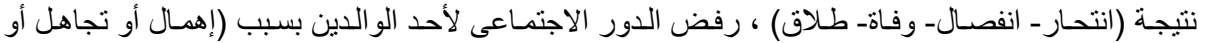

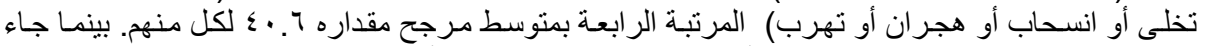

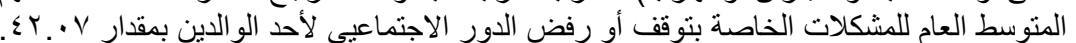

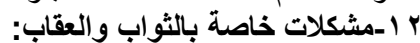

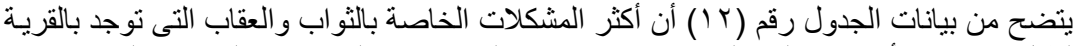

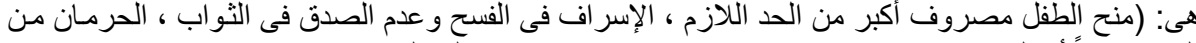

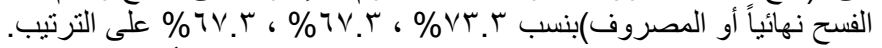

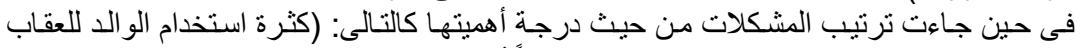

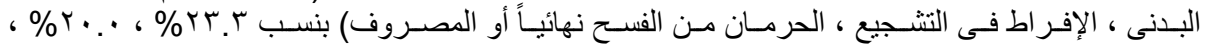

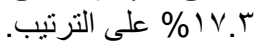

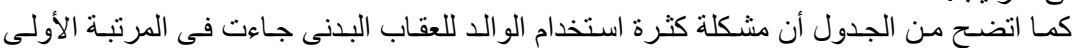

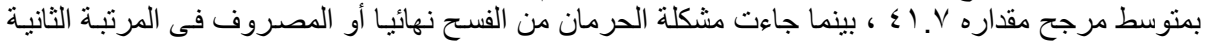

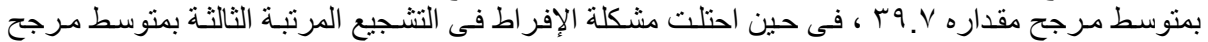

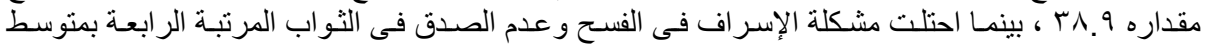

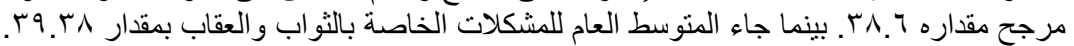

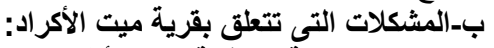
1-مشكلات خاصة بالرقابة على الأطفال:

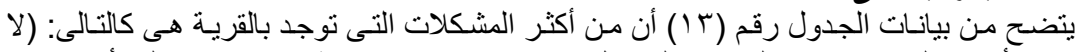

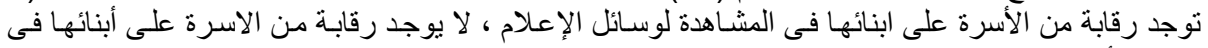

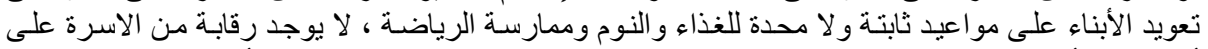

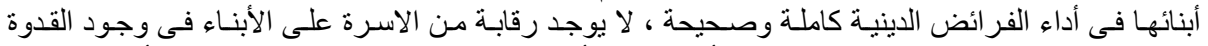

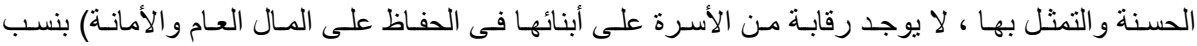

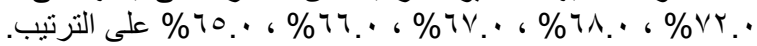

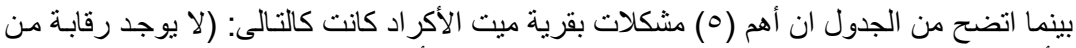

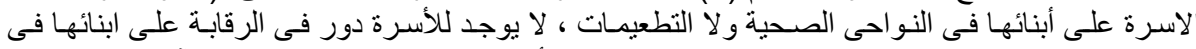

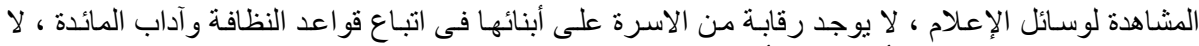

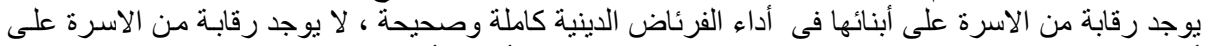

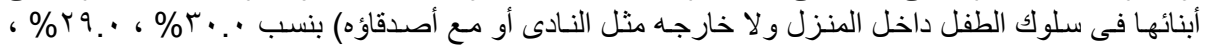

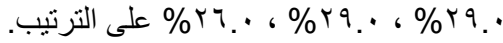


EL-Emam, M.E. and Huda M. E. Salem

$|r-1|$ 
J. Agric. Econom. and Social Sci., Mansoura Univ., Vol.2 (5), May, 2011 


\section{EL-Emam, M.E. and Huda M. E. Salem}

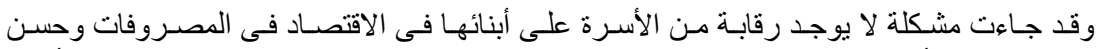

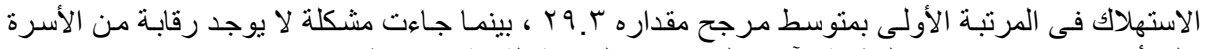

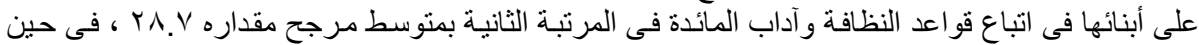

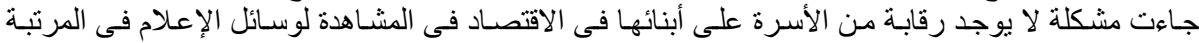

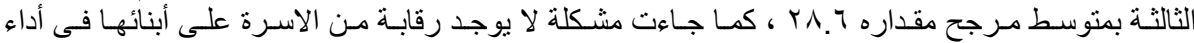

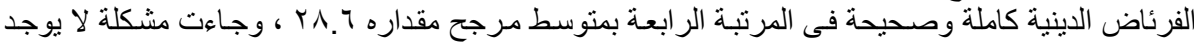

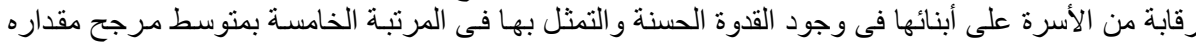

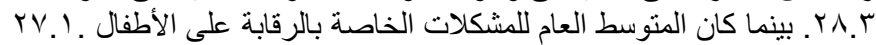

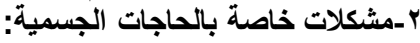

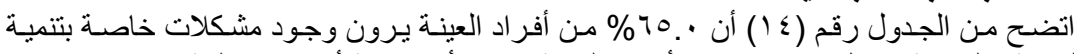

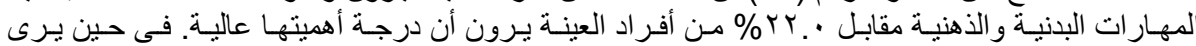

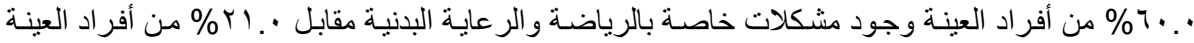

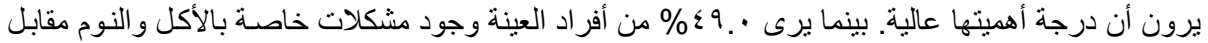

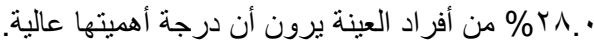

جدول رقم ( ا 1):التوزيع والنسبة المئوية لعينة المبحوثين بقرية ميت الأكراد وفقاً لوجود المشكلات الخاصـة

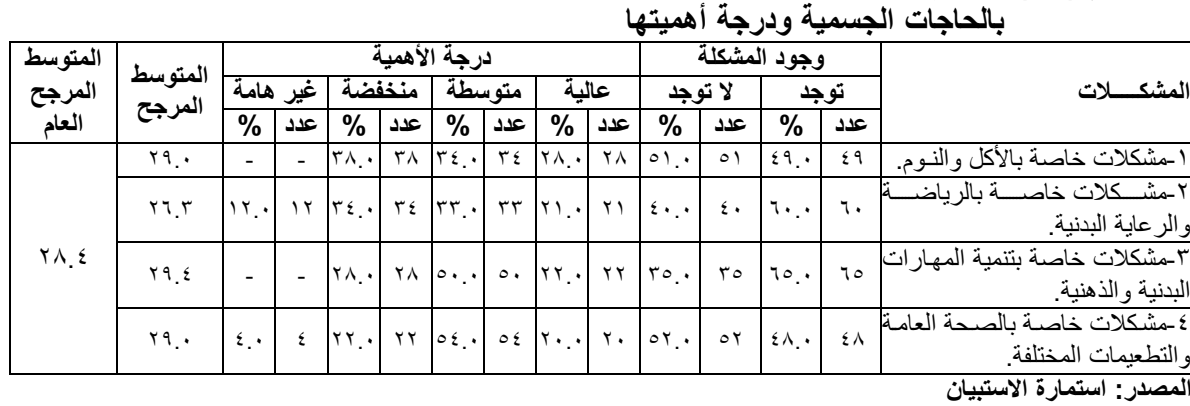

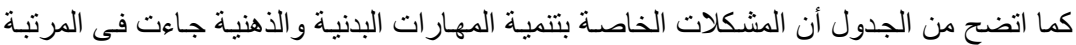

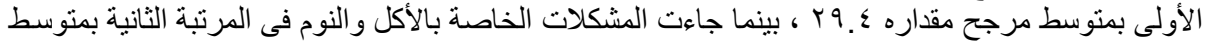

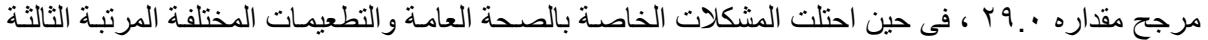

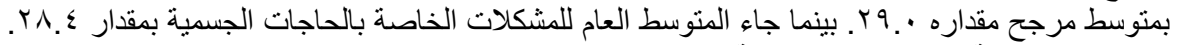

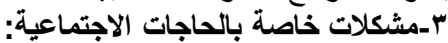

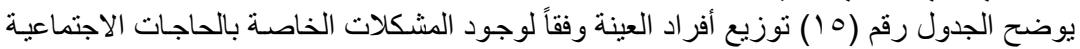

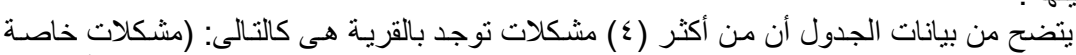
ودرجة أهميتها

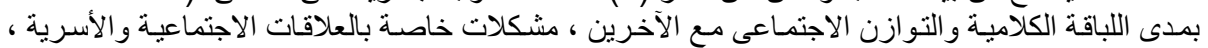

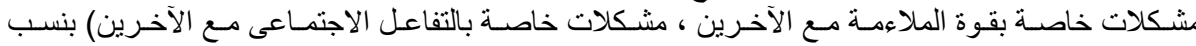

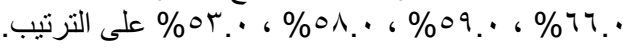

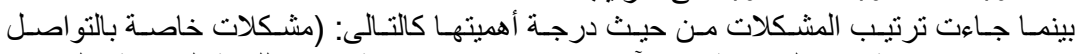

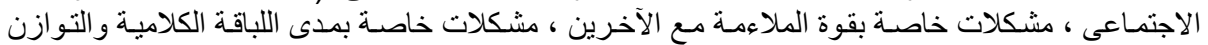

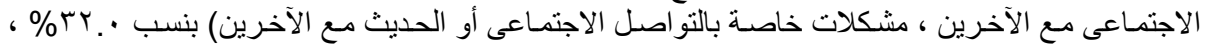

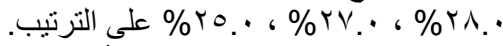

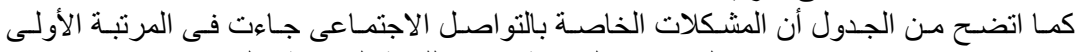

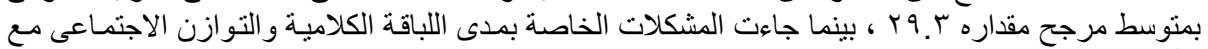

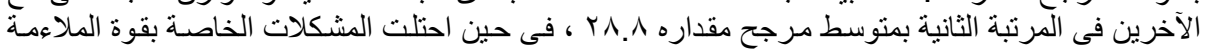

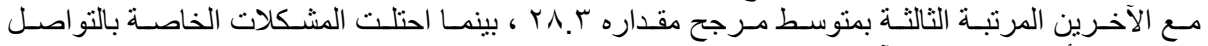

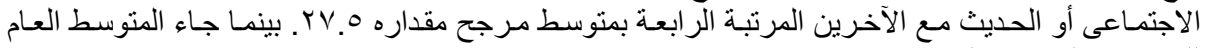


جدول رقم (0 1):التوزيع والنسبة المئوية لعينة المبحوثين بقرية ميت الأكراد وفقاً لوجود المشكلات الخاصة

\begin{tabular}{|c|c|c|c|c|c|c|c|c|c|c|c|c|c|c|}
\hline \multirow{3}{*}{ المرجح } & \multirow{3}{*}{ المرجح } & \multicolumn{8}{|c|}{ ل درجة الأهمية } & \multicolumn{4}{|c|}{ وجود المشكلة } & \multirow{3}{*}{ المشكـــلات } \\
\hline & & \multicolumn{2}{|c|}{ غير هامة } & \multicolumn{2}{|c|}{ منغفضة } & \multicolumn{2}{|c|}{ متوسطة } & \multicolumn{2}{|c|}{ عالية } & \multicolumn{2}{|c|}{ لا توجذ } & \multicolumn{2}{|c|}{ توجد } & \\
\hline & & $\%$ & عدد & $\%$ & عدد & $\%$ & عدد & $\%$ & عدد & $\%$ & عدد & $\%$ & عدد & \\
\hline \multirow{13}{*}{ YV. } & rq. & ?. & 1 & $r v$. & tr & ro.. & \multirow[t]{2}{*}{ ro } & $r . \cdot$ & rr & ¿^. & $\varepsilon \wedge$ & or. & or & 1 -مشـــــات خاصـــة بالتو اصـــل \\
\hline & \multirow{2}{*}{$r \uparrow . \wedge$} & \multirow[b]{2}{*}{$1 \cdots$} & \multirow{2}{*}{1.} & \multirow{2}{*}{ r.. } & \multirow{2}{*}{ rr } & \multirow{2}{*}{$r r^{\prime} \cdot$} & & \multirow{2}{*}{$r \cdot . \mid$} & \multirow{2}{*}{ r. } & & & & w & 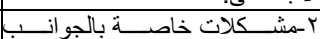 \\
\hline & & & & & & & $r \lambda$ & & & ov." & or & $\varepsilon r$. & $\varepsilon r$ & الاجنماعية. \\
\hline & $r \varepsilon . \wedge$ & 10. & 10 & rı. & ru & r.. & ri & 17. & 17 & $\leqslant 1$. & \& & 09. & 09 & 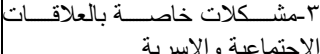 \\
\hline & & & & & & & & & & & & & & ــ-مشـكلات خاصــة بمــى اللباقــة \\
\hline & 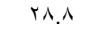 & $\therefore$ & 1 & $r v$. & re & ro.. & ro & $r v$. & rv & $r \varepsilon$. & $r \varepsilon$ & 74. & 17 & الكلاميــة و التـو ازن الاجتمـاعى مــع \\
\hline & & & & & & & & & & & & & & الآخرين. \\
\hline & rA.r & 7. & 1 & rr. & r & rr. & rr & rı. & rA & $\leqslant r$. & $\varepsilon r$ & $0{ }_{0 .}$. & 01 & هـ-مشكلات خاصة بقوة الملاءمة مع \\
\hline & & & & & & & & & & & & & & 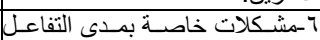 \\
\hline & rฺ.人 & $9 .{ }^{9}$ & 9 & $\Gamma \varepsilon$. & $r \xi$ & rv. & 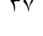 & $\Gamma \cdot \cdot$ & r. & $\sum v_{.} \cdot$ & $\xi Y$ & or." & or & الاجتماعى مع الآخرين. \\
\hline & r५.० & 7. & 1 & $\leqslant r$. & $\leqslant r$ & $r$ r. & r & 19. & 19 & 00. & 00 & ¿0. & ؛o & 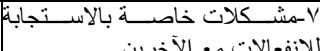 \\
\hline & & & & & & & & & & & & & & 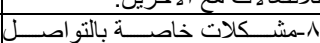 \\
\hline & rV.o & «. & $\varepsilon$ & $\leqslant$ «. & \& & rq. & rq & ro." & ro & $0 \wedge$. & 01 & $\varepsilon r$. & $\varepsilon r$ & الاجتماعى أو الحديث مع الآخرين. \\
\hline
\end{tabular}

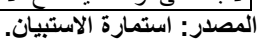

ع -مشكلات الحاجات لتحمل المسئولية بالنسبة للطفل:

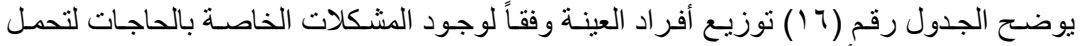

المسئولية بالنسبة للطفل ودرجة أهميتها .

جدول رقم (7 1):التوزيع والنسبة المئوية لعينة المبحوثين بقرية ميت الأكراد وفقاً لوجود المشكلات الخاصة

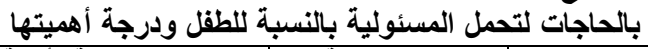

\begin{tabular}{|c|c|c|c|c|c|c|c|c|c|c|c|c|c|c|}
\hline المتوسط & & & & & لأهمي & رجة | رجة & & & & & 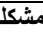 & كجود | & & \\
\hline المرجح & المنوسط & عامة & غير & ضة & منذ & مطة & & & & & & جد & & المشكــــلات \\
\hline & & $\%$ & عدد & $\%$ & عدد & $\%$ & عدد & $\%$ & عدد & $\%$ & عدد & $\%$ & عدد & \\
\hline & TV.r & ${ }^{r}$. & IT & $r \varepsilon$. & $r \leqslant$ & 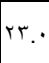 & rT & r.. & ri & «ะ. & $\leqslant \varepsilon$ & 07. & 07 & 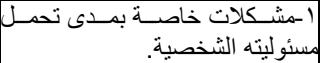 \\
\hline rg & $r \cdot .1$ & - & - & $r \wedge$. & rᄉ & $\leqslant r$. & $\leqslant r$ & rq. & rq & r. & rT & i1. & 71 & مسئوليته الدرات اسية. \\
\hline 17.1 & $r \cdot .1$ & - & - & rq. & דו & $\leqslant \vee$. & $\leqslant V$ & $r v$. & TV & $\leqslant 0$. & $\leqslant 0$ & 00. & 00 & |r-مشئوليته الأسرية. \\
\hline & r9.० & 7. & 7 & ri.. & ri & ro. & ro & r৯. & rA & rq. & rq & 71. & 71 & 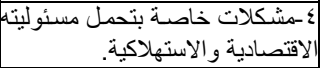 \\
\hline
\end{tabular}

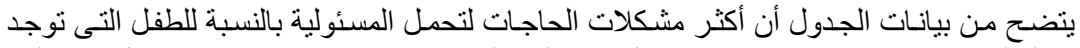

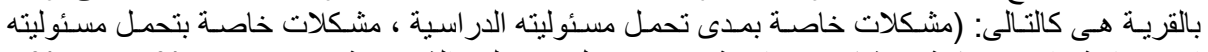

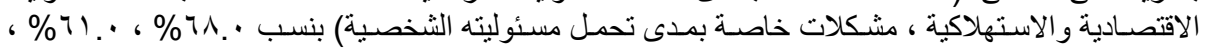

بينما جاءت ترتيب المشكلات من حيث درجـة أهميتها كالتالى: (مشكلات خاصـة بتحمل مسئوليته

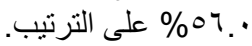

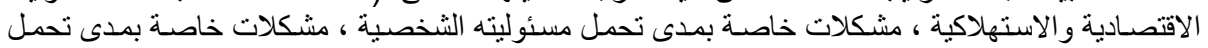

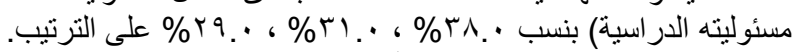

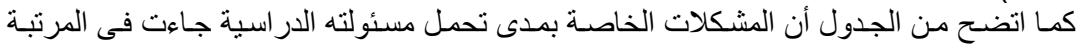

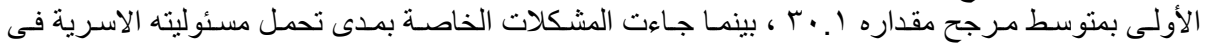




\section{EL-Emam, M.E. and Huda M. E. Salem}

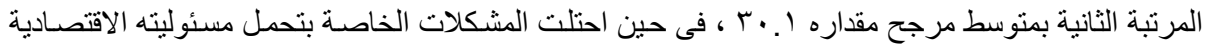

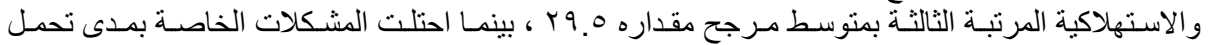

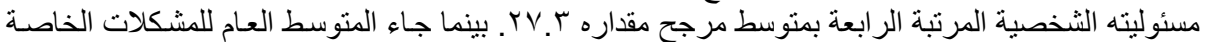

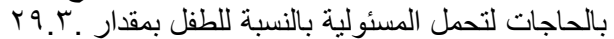

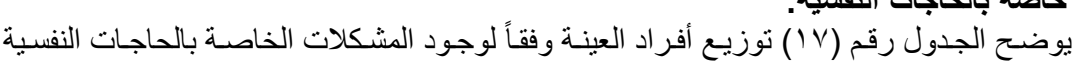
0-مشكلات خاصة بالحاجات النفسية: ودرجة أهميتها .

جدول رقم (IV):التوزيع والنسبة المئوية لعينة المبحوثين بقرية ميت الأكراد وفقاً لوجود المشكلات الخاصة

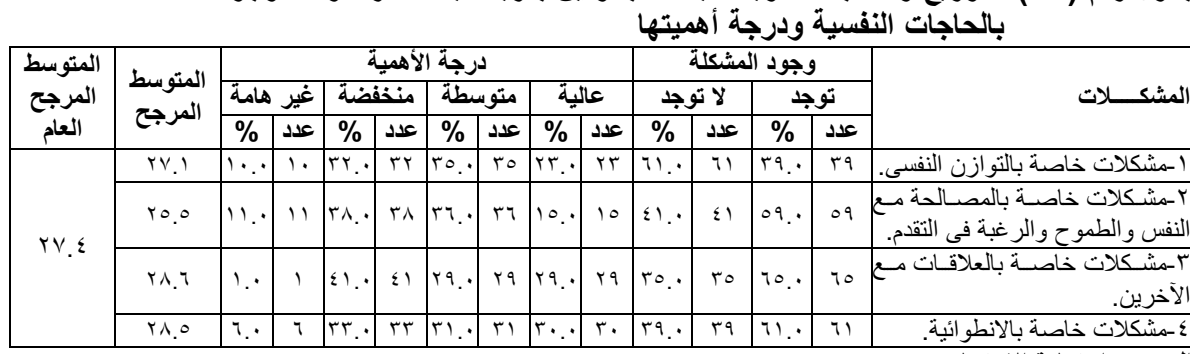
المصدر: استمارة الاستبيان.

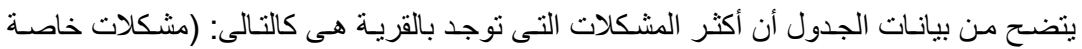

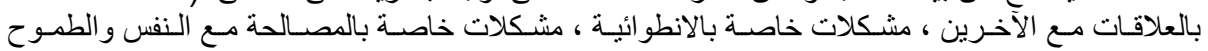

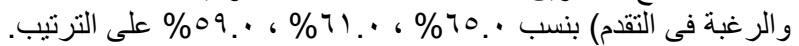

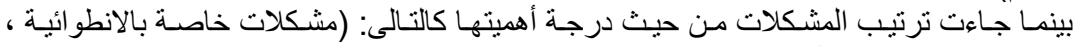

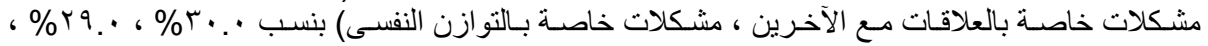

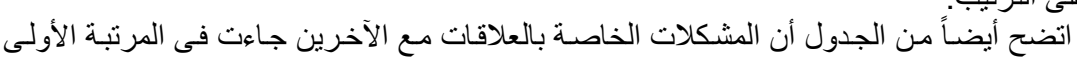

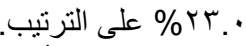

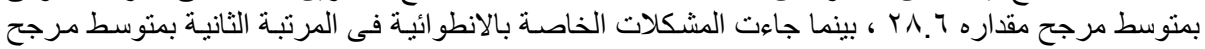

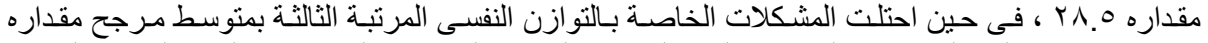

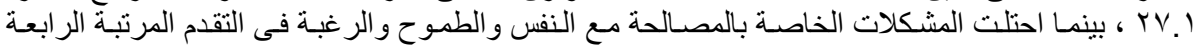

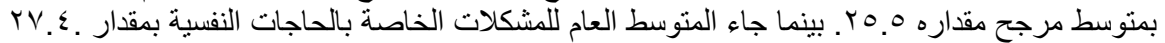
7-مشكلات خاصة بالحاجات الثقافية:

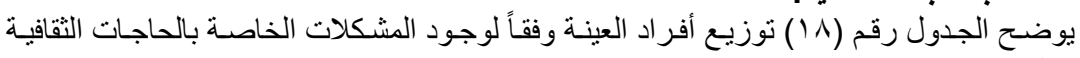
ودرجة أهميتها.

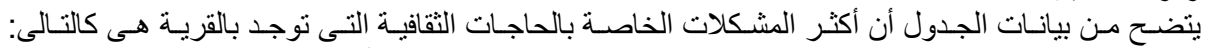

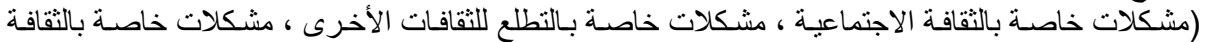

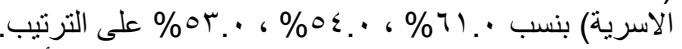

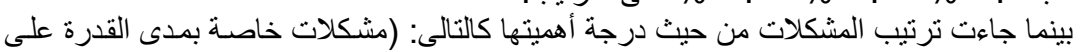

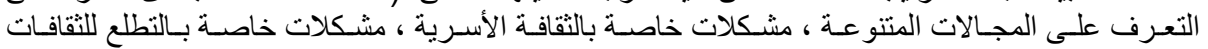

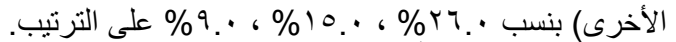

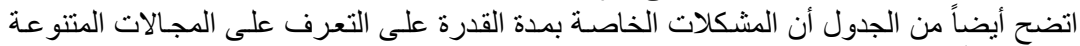

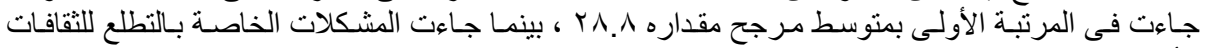

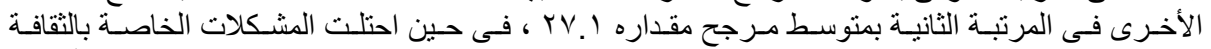

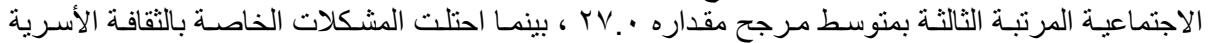

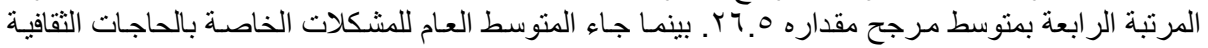


J. Agric. Econom. and Social Sci., Mansoura Univ., Vol.2 (5), May, 2011

جدول رقم (1 1):التوزيع والنسبة المئوية لعينة المبحوثين بقرية ميت الأكراد وفقاً لوجود المشكلات الخاصة

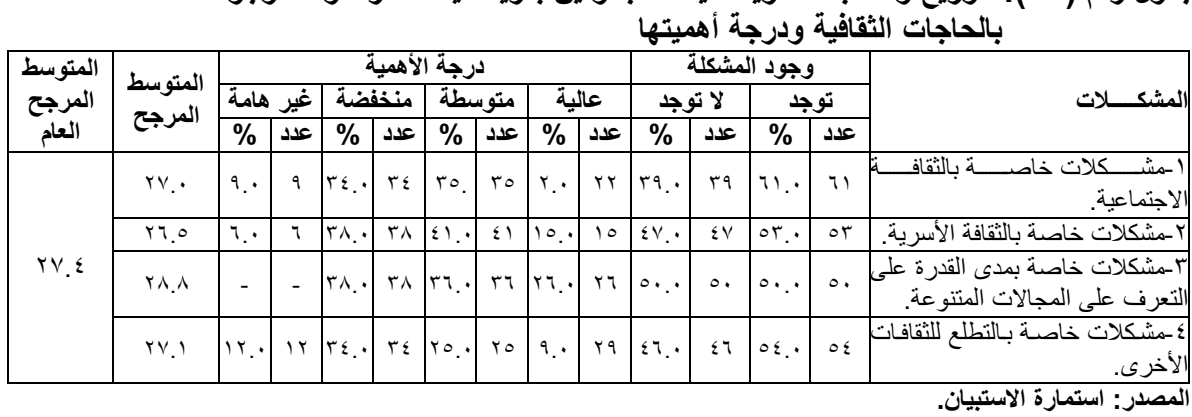

V -مشكلات خاصة بالحاجات الاقتصادية: يوضح الجدول رقم (9 (1) ) توزيع أفر اد العينة وفقاً لوجود المشكلات الخاصـة بالحاجات الاقتصـادية

$$
\text { ودرجة أهميتها. }
$$

جذول رقم (9 (1):التوزيع والنسبة المئوية لعينة المبحوثين بقرية ميت الأكراد وفقاً لوجود المشكلات الخاصة بالحاجات الاقتصادية ودرجة الهية الهميتها

\begin{tabular}{|c|c|c|c|c|c|c|c|c|c|c|c|c|c|c|}
\hline \multirow{3}{*}{ المرجت العام } & \multirow{3}{*}{ المترجط } & \multicolumn{8}{|c|}{ درجة الأهمية } & \multicolumn{4}{|c|}{ وجود المشكلة } & \multirow{3}{*}{ |المشكــــلات } \\
\hline & & \multicolumn{2}{|c|}{ غير هامة } & \multicolumn{2}{|c|}{ منخفضة } & \multicolumn{2}{|c|}{ متوسطة } & \multicolumn{2}{|c|}{ عالية } & \multicolumn{2}{|c|}{ لا توجد } & \multicolumn{2}{|c|}{ توجد } & \\
\hline & & $\%$ & عدد & $\%$ & عدد & $\%$ & عدد & $\%$ & علد & $\%$ & عدد & $\%$ & عدد & \\
\hline \multirow{4}{*}{ rA. 9} & rq. & - & - & rı. & rA & or. & or & $r \cdot \cdot \mid$ & $r$. & $r \leqslant$. & $\Gamma \varepsilon$ & 77. & 77 & | الانفاق. كـــات خلاصــــة بالصـــرف \\
\hline & $r \cdot .0$ & - & - & .r & rr & 01. & 01 & $r v$. & YV & $\varepsilon v$. & $\leqslant v$ & or. & or & في المصركلات خاصـة بحسن اليومس. \\
\hline & r9.० & 7. & 1 & $r v$. & rV & rr. & r & $r \leq$. & $r \varepsilon$ & rq. & rq & 7. & 71 & |الأسرىكلات خاصة بحسن الاستهلاك \\
\hline & r.. & $1 \cdot$. & 1. & r.. & ri & rr. & rr & rr.. $\mid$ & rY & «^.. & $\leqslant 1$ & or. & or & الأسرية. العـام وعـدم إهـار الأمسوال \\
\hline
\end{tabular}

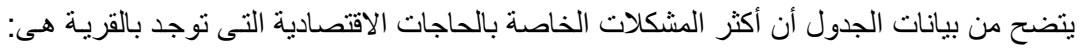

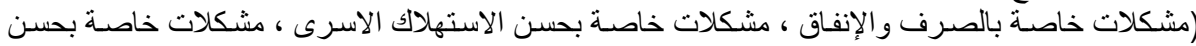

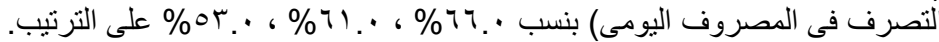

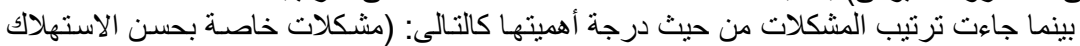

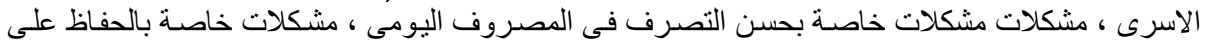

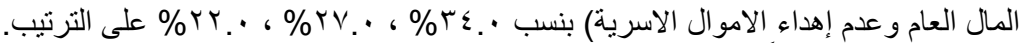

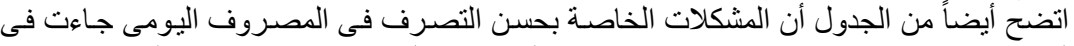

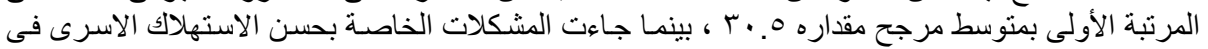

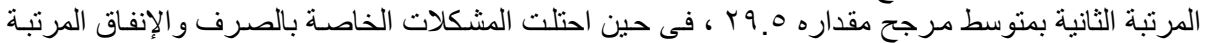

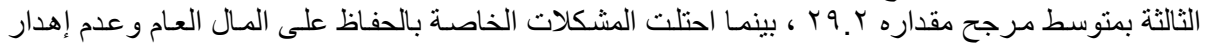

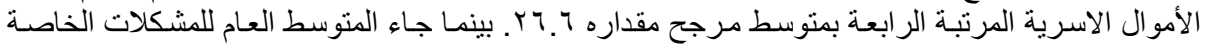

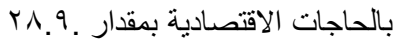
1-مشكلات خاصة بالتوجية:

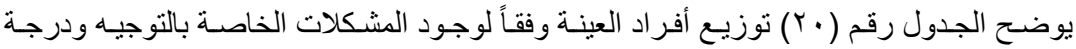
أهميتها .

جدول رقم ( • (ب):التوزيع والنسبة المئوية لعينة المبحوثين بقرية ميت الأكراد وفقاً لوجود المشكلات الخاصة بالتوجيه ودرجة أهميتها 


\section{EL-Emam, M.E. and Huda M. E. Salem}

\begin{tabular}{|c|c|c|c|c|c|c|c|c|c|c|c|c|c|c|}
\hline \multirow{3}{*}{ المرجتح العام } & \multirow{3}{*}{ المرجح } & \multicolumn{8}{|c|}{ درجة الأهمية } & \multicolumn{4}{|c|}{ وجود المشكلة } & \multirow{3}{*}{ المشكــــلات } \\
\hline & & \multicolumn{2}{|c|}{ غيز هامة } & \multicolumn{2}{|c|}{ منخفضة } & \multicolumn{2}{|c|}{ متوسطة } & \multicolumn{2}{|c|}{ عالية } & \multicolumn{2}{|c|}{ لا توجد } & \multicolumn{2}{|c|}{ توجد } & \\
\hline & & $\%$ & عدد & $\%$ & عدد & $\%$ & عدد & $\%$ & عدد & $\%$ & عدد & $\%$ & عدد & \\
\hline \multirow{5}{*}{ rV.r } & r.. & 11. & 11 & rı. & $r \wedge$ & rq. & rq & rr. & rY & rA. & ru & $V Y_{.} \cdot$ & VY & | -سوء توجيه المعلم للتناميذ. \\
\hline & rq.1 & 1. & 1 & rv. & rv & rt. & rr & $r \cdot \cdot$ & r. & $r \leqslant$. & $r \varepsilon$ & จ५. & V4 & 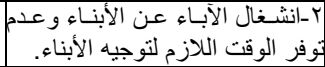 \\
\hline & TV.V & $1 \cdot \cdot$ & $1 \cdot$ & rr. & זr & $r v$. & rv & $r \cdot . \cdot$ & $r$. & rt. & r & $71 . \cdot$ & 11 & 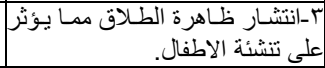 \\
\hline & $r V . \varepsilon$ & $9 . \cdot$ & 9 & $r \leqslant . \cdot$ & $r \varepsilon$ & 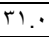 & $r$ & 7.. & ry & rr. & $r \pi$ & $7 V$. & TV & ــانتشار الأمية بين بعض الأمهات. \\
\hline & ro.9 & $1 \cdot \cdot$ & 1. & $\varepsilon$. & $\leqslant r$ & $r v$. & rv & r... & r) & $\leq 0$. & <0 & 00. & 00 & 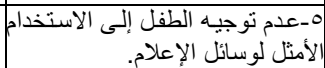 \\
\hline
\end{tabular}

يتضح من بيانات الجدول أن أكثر الشكاتلات الخاصـة بالتوجيه التى توجد بالقرية هـى: (انثـال

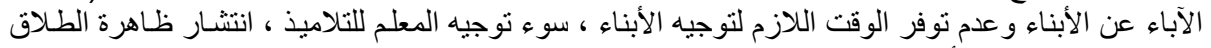

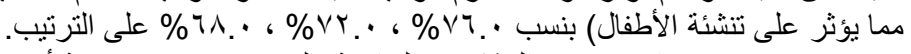

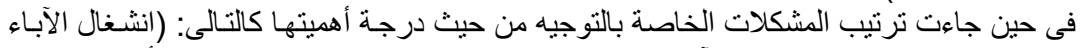

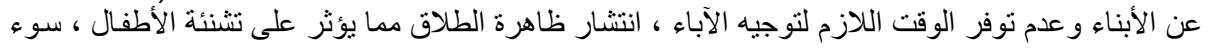

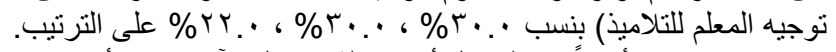

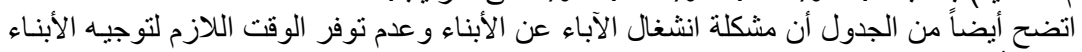

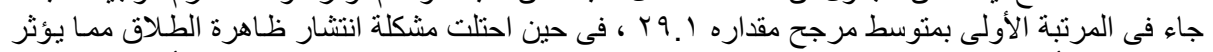

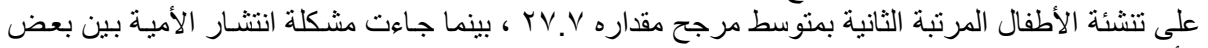

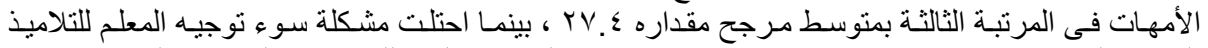

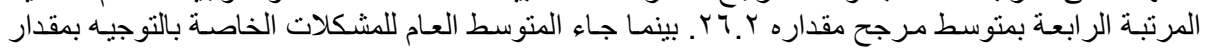

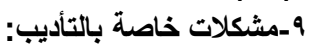

يوضـح الجدول رقم ( (r) توزيع أفر اد العينـة وفقاً لوجود الشككلات الخاصـة بالتأديب ودرجـة

أهيتها .

جدول رقم ( إ) :التوزيع والنسبة المئوية لعينة المبحوثين بقرية ميت الأكراد وفقاً لوجود المثكلات الخاصة بالتأديب ودرجة أهميتها

\begin{tabular}{|c|c|c|c|c|c|c|c|c|c|c|c|c|c|c|}
\hline \multirow{3}{*}{ المرجح } & \multirow{3}{*}{ المرجح } & \multicolumn{8}{|c|}{ درجة الأهمية } & \multicolumn{4}{|c|}{ وجود المشكلة } & \multirow{3}{*}{ |المشكـــلات } \\
\hline & & \multicolumn{2}{|c|}{ غير هامة } & \multicolumn{2}{|c|}{ منخفضة } & \multicolumn{2}{|c|}{ متوسطة } & \multicolumn{2}{|c|}{ عالية } & \multicolumn{2}{|c|}{ لا لا توجذ } & \multicolumn{2}{|c|}{ توجل } & \\
\hline & & $\%$ & عدد & $\%$ & عدد & $\%$ & عدد & $\%$ & عدد & $\%$ & عدد & $\%$ & عدد & \\
\hline \multirow{4}{*}{ หч. } & $r v .9$ & - & - & $\varepsilon r$. & $\leqslant r$ & r. & $r v$ & r.. & r) & $0 \Lambda_{.}$. & 01 & $\varepsilon r$. & $\varepsilon r$ & |-عدم تعويد الطفل على الصدق \\
\hline & $r \cdot .1$ & ir. & ir & rı. & rᄉ & rq. & rq & 1.. & $r_{1}$ & or. & or & $\varepsilon r$. & $\varepsilon$ & †-عدم تعويد الطفل على عدم إي \\
\hline & YA.Y & - & - & rr. & rr & or. & or & 10. & 10 & $£ 0$. & £o & 00. & 00 & لآ-سو ء معاملة الو الدين للأطفال. \\
\hline & r৭.r & - & - & r.. & דו & 00. & 00 & 19. & 19 & $\{\wedge$. & « & or. & or & 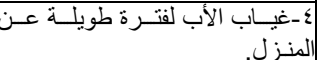 \\
\hline
\end{tabular}

يتضح من بيانات الجدول أن أكثر المشكلات الخاصة بالتأديب التى توجد بالقرية هى: (سوء معاملة الفئة

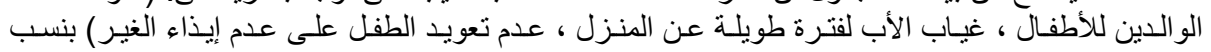

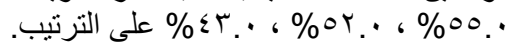

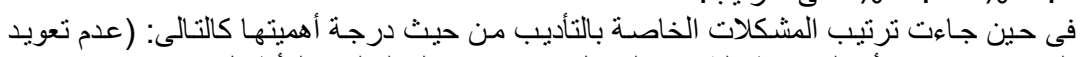

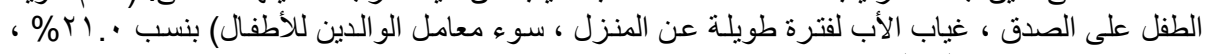

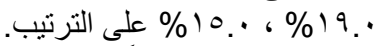

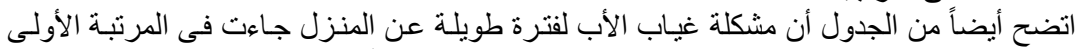

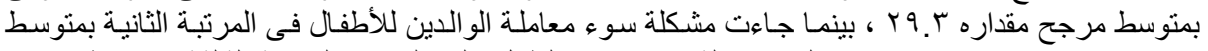

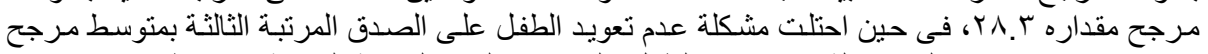

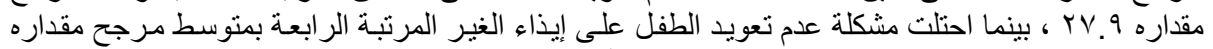

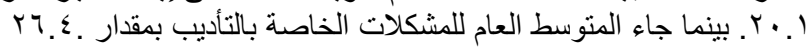


1 ا-مشكلات خاصة بالر عاية أو التحكم:

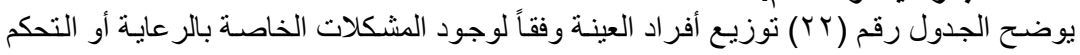
ودرجة أهميتها .

جدول رقم (Yr):التوزيع والنسبة المئوية لعينة المبحوثين بقرية ميت الأكراد وفقاً لوجود المشكلات الخاصة

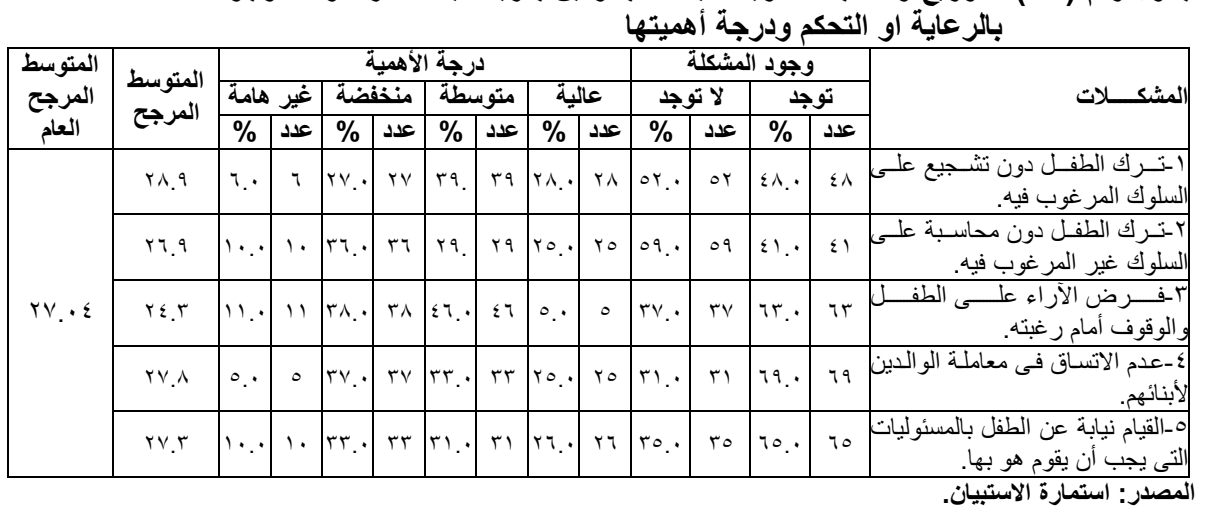

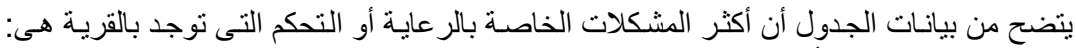

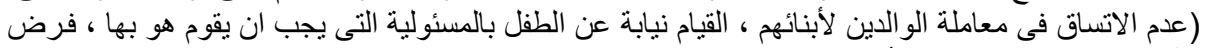

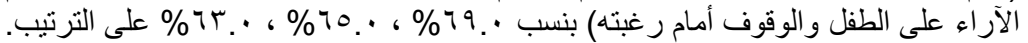

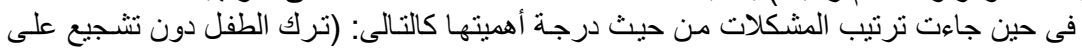

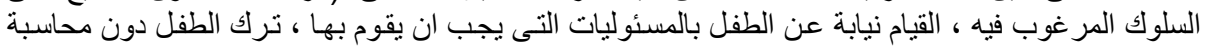

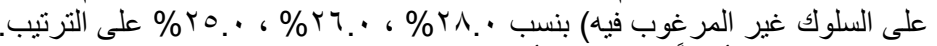

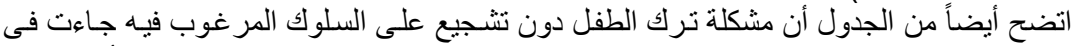

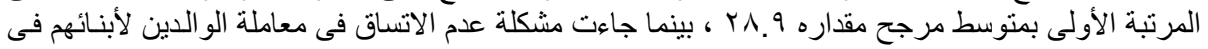

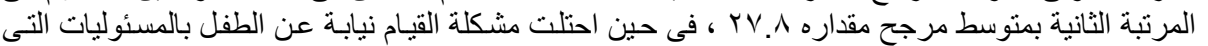

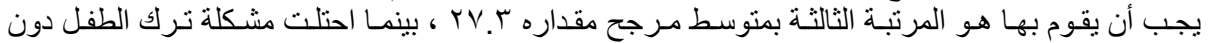

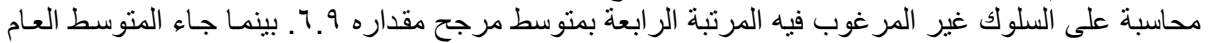

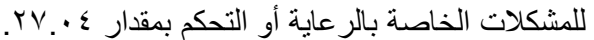

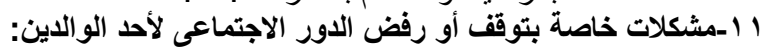

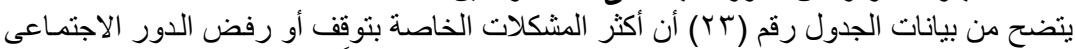

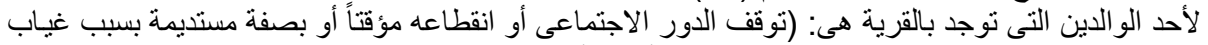

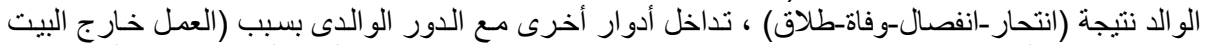

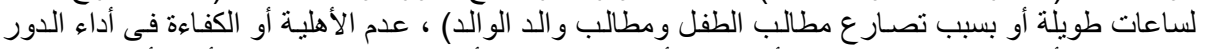

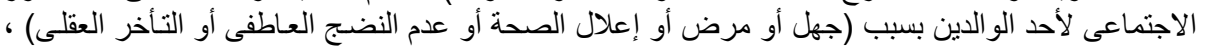

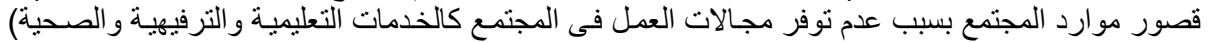

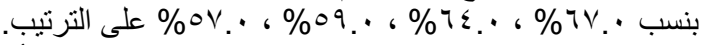

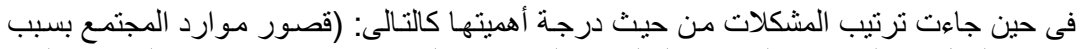

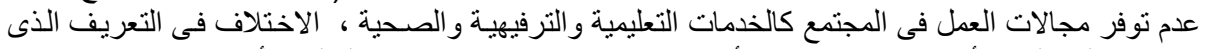

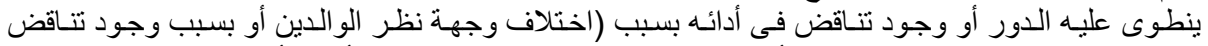

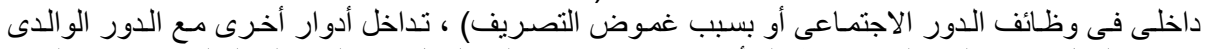

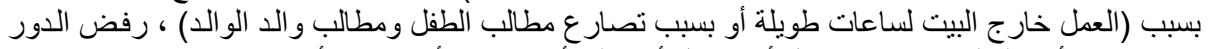

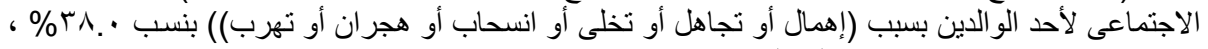

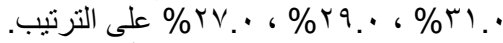

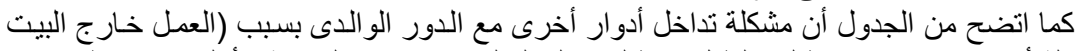

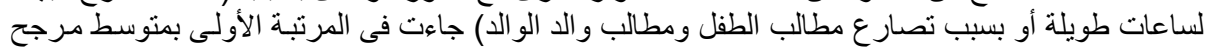




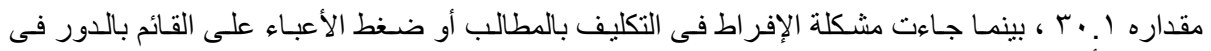

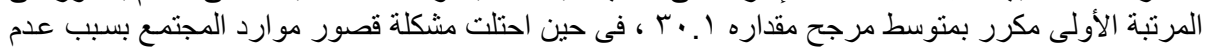

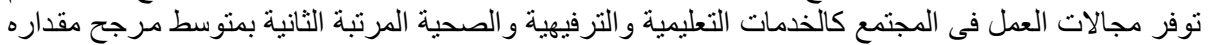

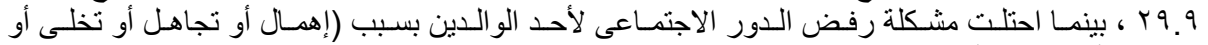

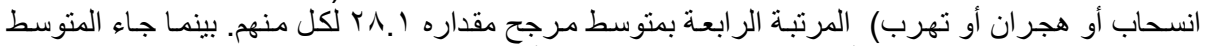

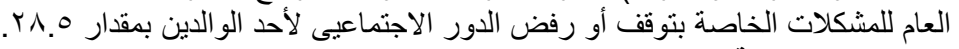

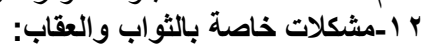

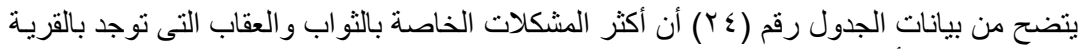

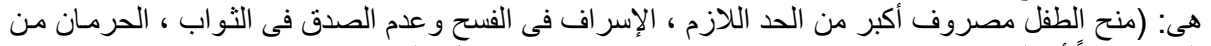

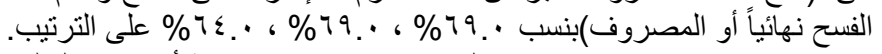

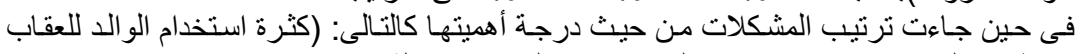

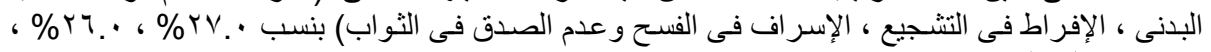

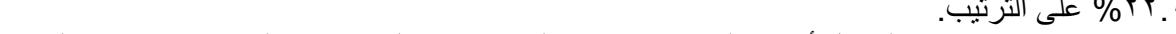

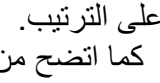

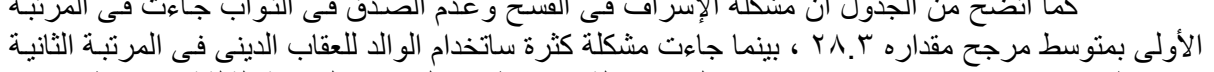

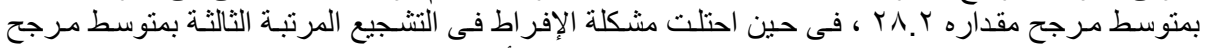

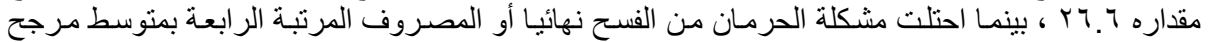

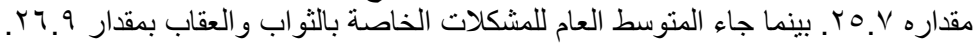


J. Agric. Econom. and Social Sci., Mansoura Univ., Vol.2 (5), May, 2011

$r \varepsilon_{-} r T$

490 


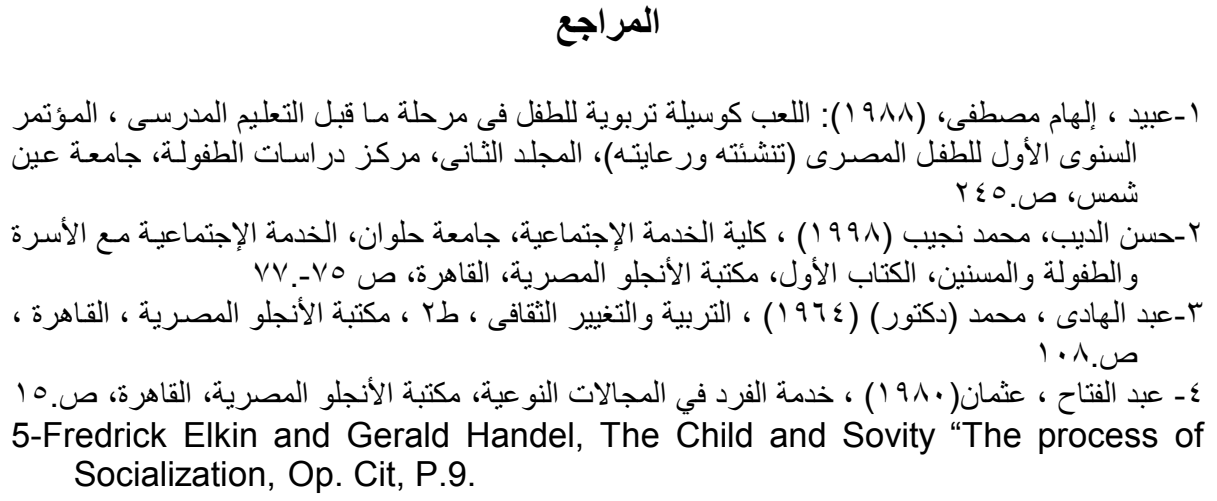$$
\text { المراجع }
$$

\title{
THE PROBLEMS FACING CHILDREN AND THE ROLE OF THE RURAL FAMILY IN CONTROLLING THEM DURING THE SOCIALIZATION PROCESS "A FIELD STUDY AT TWO VILLAGES IN DAKAHLIA GOVERNORATE"
}

\section{El-Emam, M.E. and Huda M. E. Salem}

Agric. Extension and Rural Sociology Dept., Fac. Agric., Mans.Univ.

\begin{abstract}
The main objective of this is to identify the problems facing children and the family's role in controlling them at the study villages. To achieve this objective, the rural community was selected as a geographical framework for carrying out the study. Two villages at Dakahlia governorate were selected; Salamoon EL-Qomash and Meet EL-Akrad where 150 families from Salamoon EL-Qomash village and 100 families from Meet EL-Akrad village.

The current study used a descriptive method which interests in studying the problems of the current situation as it describes the problems related to control on children and the degree of their importance at the current time. A number of statistical methods which suit the nature of the collected data were used. Frequencies and percentages were used to describe the sample and weighted mean was used to order these problems.

The results indicated that most of the problems that face children came as follows: (there is no control of the family on their children in the performance of complete and correct religious obligation, the presence of role models and assimilation by, maintaining public money and the honesty, watching the media, accustom the child on fixed and specific dates for eating, sleeping and sporting) representing $73.3 \%, 70.7 \%, 67.3 \%, 67.3 \%$, and $66.0 \%$ of the sample individual, respectively.

Moreover, the following problems came as the most important problems: (there is no control of the family on their children to follow the rules of hygiene and table etiquette, health and vaccinations aspects, how to selfreliance and non-negligent, respect elderly and provide aid to them in times of need and respect neighbors and relatives, the child's behavior inside ands
\end{abstract}


outside the house in the club or with his friends). These problems represent $34.7 \%, 30.0 \%, 26.7 \%, 26.0 \%$, and $25.3 \%$ of the total sample, respectively.

The problem of no control of the family on their children in the presence of role models and assimilation by came in the first rank with weighted mean of 45.8, while the problem of no control of the family on their children to follow the rules of hygiene and table etiquette had the second place with weighted mean of 44.3, while the problem of no control of the family on their children in rationalizing the expenditure and consumption came in third place with a weighted mean of 42.5 . Moreover, the problem of no control of the family on their children in respect the elderly and provide aid to them in times of need and respect neighbors and relatives came in fourth place with a weighted mean of 41.5 , and the problem of no control of the family on their children in behavior of the child inside and outside the house such as in club or friends in the fifth rank with a weighted mean of 41.2. Generally, the overall weighed mean of the problems on the children controlling was 39.3 .

كلية الزراعة - جامعة المنصورة كلية الزراعة - جامعة الاسكندرية

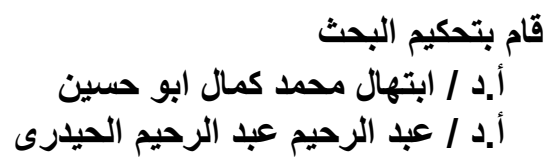

قام بتحكيم البحث أ.د / عبد الرحيم عبد الرحيم الحيدرى الرين 
EL-Emam, M.E. and Huda M. E. Salem 


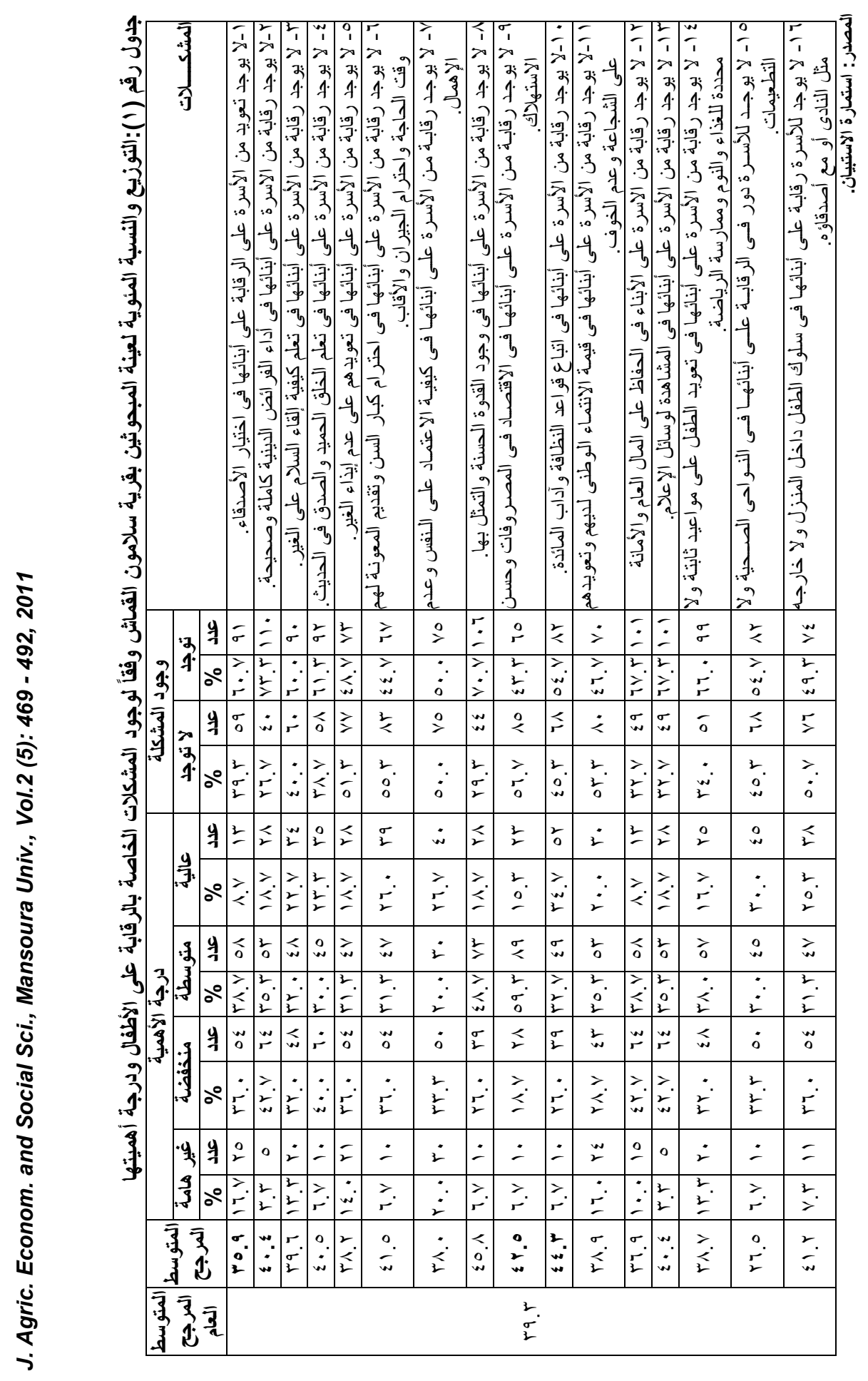



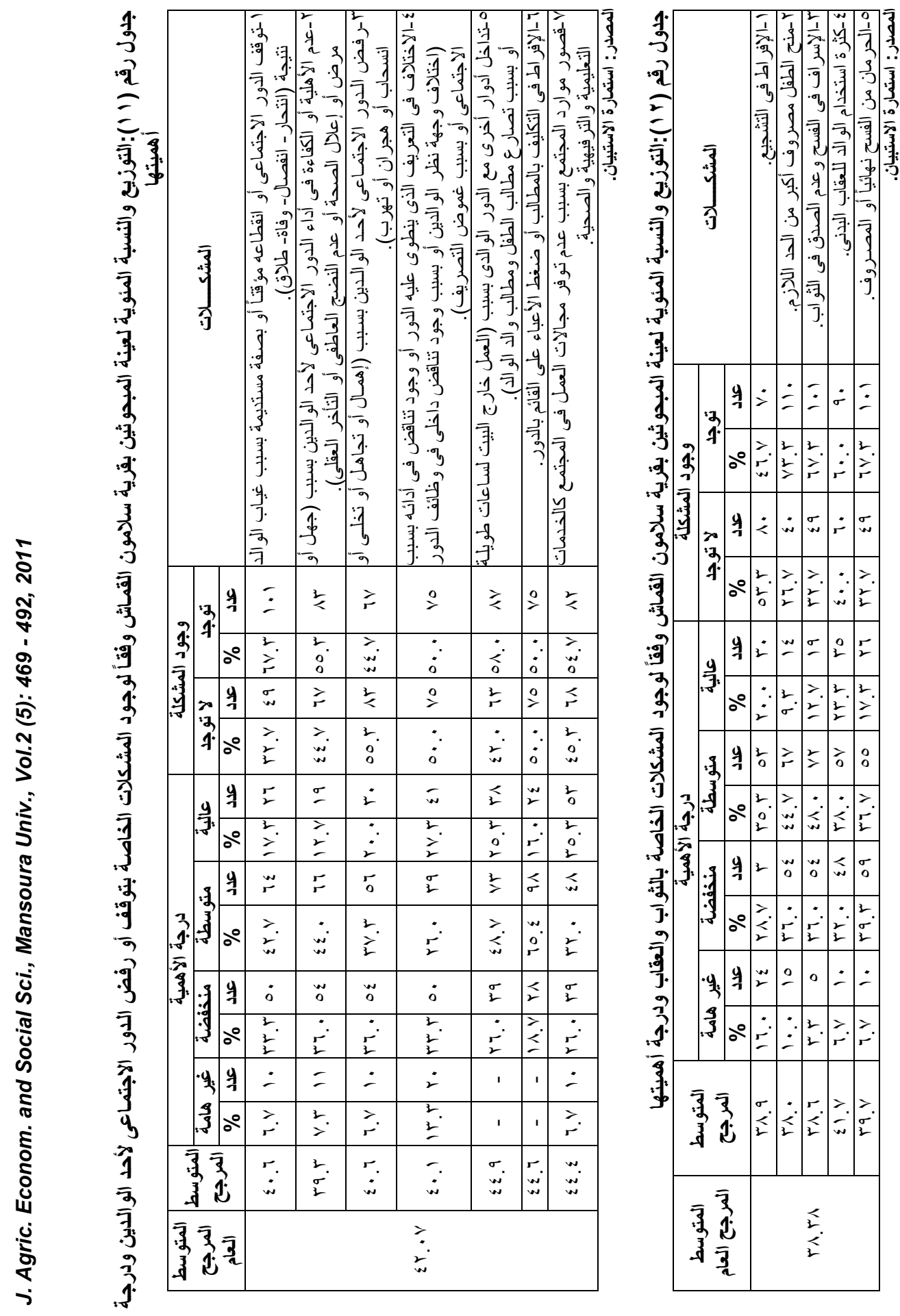

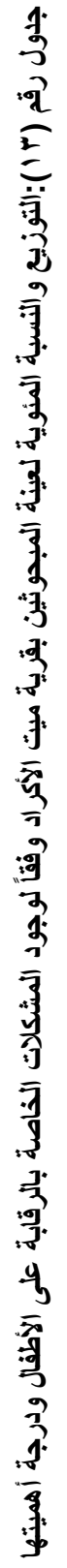




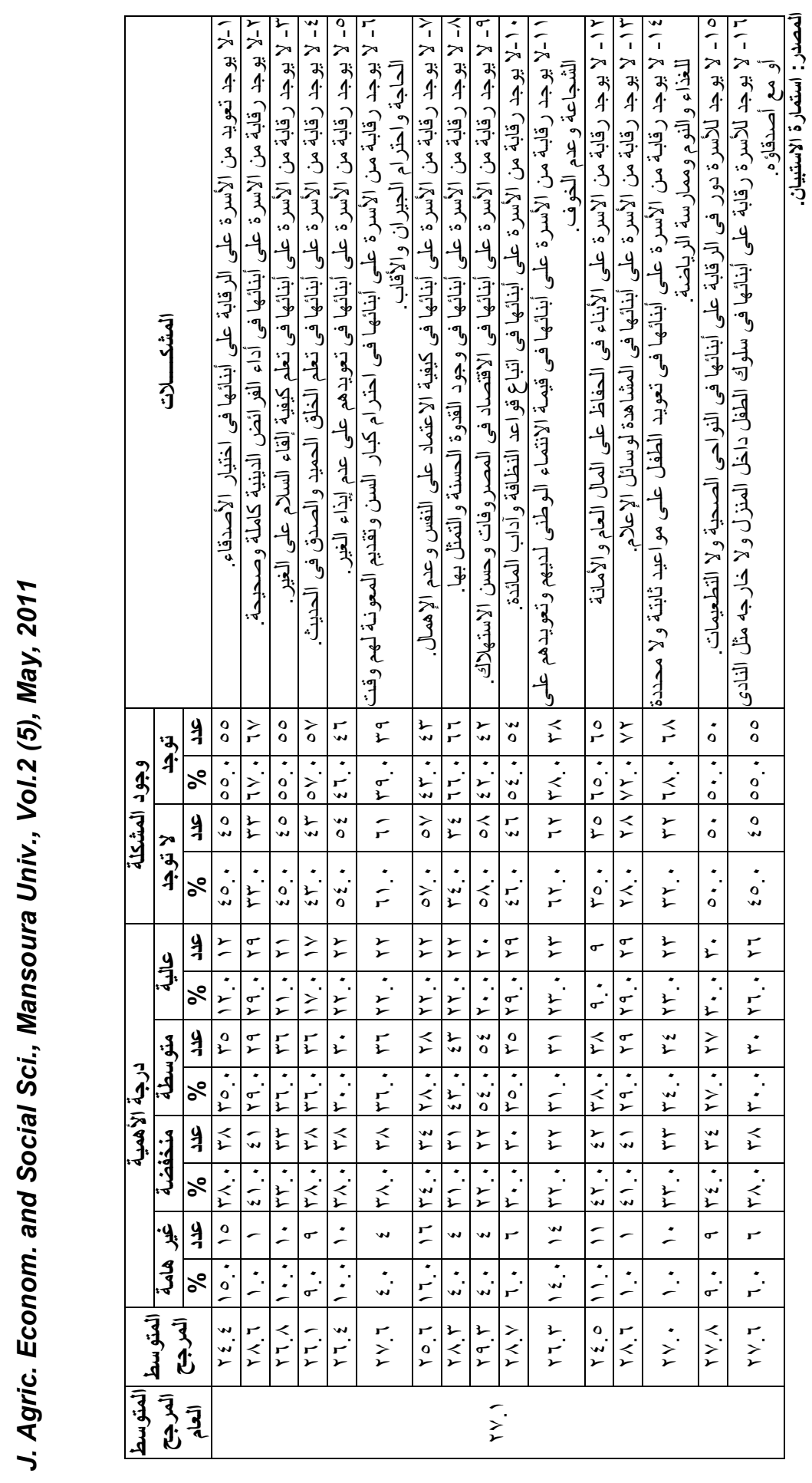

응 


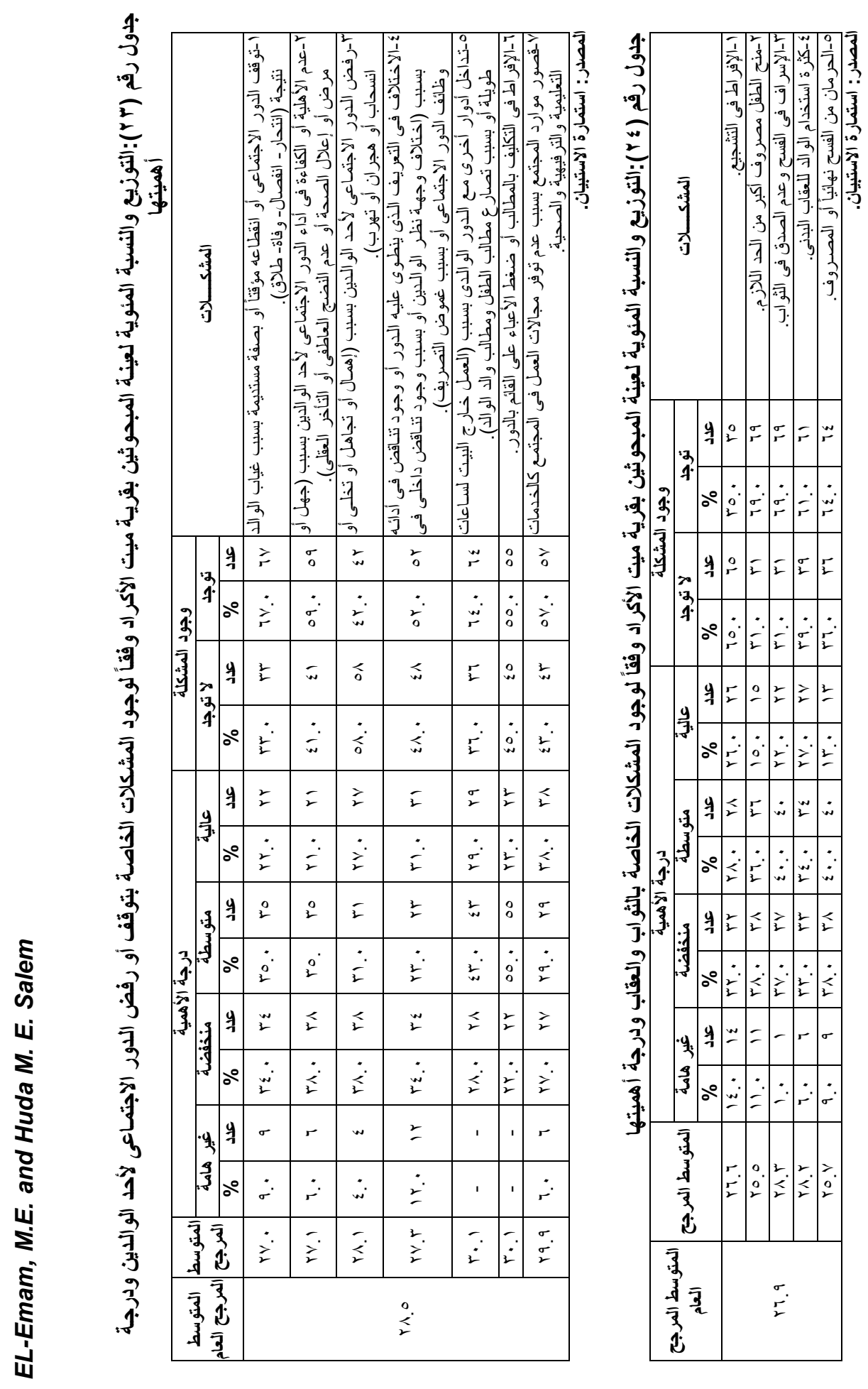

Б) 